NBER WORKING PAPER SERIES

BIDDING RINGS AND THE WINNER'S CURSE:
THE CASE OF FEDERAL OFFSHORE OIL AND GAS LEASE AUCTIONS

Ken Hendricks

Robert Porter

Guofu Tan

Working Paper 9836

http://www.nber.org/papers/w9836

\author{
NATIONAL BUREAU OF ECONOMIC RESEARCH \\ 1050 Massachusetts Avenue \\ Cambridge, MA 02138 \\ July 2003
}

We received helpful comments from Jacques Cremer, Glenn Ellison, and from the particpants in a number of seminars. David Barth and Heng Ju provided capable research assistance. Hendricks and Tan received financial support from the SSHRC, and Porter from the NSF. The views expressed herein are those of the authors and not necessarily those of the National Bureau of Economic Research

(C)2003 by Ken Hendricks, Robert Porter, and Guofu Tan. All rights reserved. Short sections of text not to exceed two paragraphs, may be quoted without explicit permission provided that full credit including $\subset$ notice, is given to the source. 
Bidding Rings and the Winner's Curse: The Case of Federal Offshore Oil and Gas Lease Auctions Ken Hendricks, Robert Porter, and Guofu Tan

NBER Working Paper No. 9836

July 2003

JEL No. C7, D4, L1

\section{ABSTRACT}

This paper extends the theory of legal cartels to affiliated private value and common value environments, and applies the theory to explain joint bidding patterns in U.S. federal government offshore oil and gas lease auctions. We show that efficient collusion is always possible in private value environments, but may not be in common value environments. In the latter case, fear of the winner's curse can cause bidders not to bid, which leads to inefficient trade. Buyers with high signals may be better off if no one colludes. The bid data is consistent with oil and gas leases being common value assets, and with the prediction that the winner's curse can prevent rings from forming on marginal tracts.

Ken Hendricks

Department of Economics University of Texas

Austin, TX 78712

hendrick@eco.utexas.edu
Robert Porter Department of Economics Northwestern University Evasnton, IL 60208 and NBER

r-porter@northwestern.edu
Guofu Tan

Department of Economics University of British Columbia Vancouver, BC

Canada V6T 1Z1

gtan@interchange.ubc.ca 


\title{
Bidding Rings and the Winner's Curse: The Case of Federal Offshore Oil and Gas Lease Auctions*
}

\author{
Ken Hendricks, Robert Porter, and Guofu Tan
}

June 19, 2003

\begin{abstract}
This paper extends the theory of legal cartels to affiliated private value and common value environments, and applies the theory to explain joint bidding patterns in U.S. federal government offshore oil and gas lease auctions. We show that efficient collusion is always possible in private value environments, but may not be in common value environments. In the latter case, fear of the winner's curse can cause bidders not to bid, which leads to inefficient trade. Buyers with high signals may be better off if no one colludes. The bid data is consistent with oil and gas leases being common value assets, and with the prediction that the winner's curse can prevent rings from forming on marginal tracts.
\end{abstract}

\section{Introduction}

Collusion in an auction market occurs when a group of bidders take actions to limit competition among themselves. Colluding bidders are often called a ring, which can include all of the bidders or some subset. There is evidence of collusion in many auction markets. Examples include highway construction contracts (Porter and Zona [27], school milk delivery (Pesendorfer [25], Porter and Zona [28]), and timber auctions (Baldwin et al.[3]). Collusion is not too surprising since noncooperative behavior

\footnotetext{
${ }^{*}$ Hendricks: Department of Economics, University of Texas, Austin, TX 78712. Porter: Department of Economics, Northwestern University, Evanston, IL 60208. Tan: Department of Econommics, University of British Columbia, Vancouver, BC, Canada V6T 1Z1. We received helpful comments from Jacques Cremer, Glenn Ellison, and from the particpants in a number of seminars. David Barth and Heng Ju provided capable research assistance. Hendricks and Tan received financial support from the SSHRC, and Porter from the NSF.
} 
is not jointly optimal for bidders. They are collectively better off colluding and transferring gains from trade from the seller to the ring. The problems that a ring faces in dividing the collusive surplus are detection by authorities or by the seller, internal enforcement, entry, and private information about the gains from trade. Legal rings do not have to worry as much about detection or enforcement. The main obstacle that they face is offering incentives to elicit each member's private information about the gains to trade. This raises the following question: can a legal ring collude efficiently and still offer its members expected payoffs that exceed what they can earn if the ring does not operate?

The question has been studied using the tools of mechanism design for auctions of private value assets with independent signals. Private value assets are assets where each buyer's valuation depends only upon her own information. Examples include highway construction contracts where the variation in the buyers' valuations is due to idiosyncratic differences in costs. The conclusion of the literature is that bidding rings can collude efficiently and make their members better off. Our objective in this paper is to study ring formation in first-price sealed-bid auctions of private value assets with affiliated signals and common value assets. Common value assets are assets where each buyer's valuation depends upon the information of all of the buyers. The canonical example of such assets are oil and gas leases. The value of the oil and gas deposit on a tract is common to all bidders, even though they may have different information about the size of the deposit and different development costs. ${ }^{1}$

The motivation for our study is to explain the incidence of joint bidding in U.S. federal auctions of oil and gas leases in the Outer Continental Shelf off the coasts of Louisiana and Texas during the period 1954 to 1970, inclusive. Joint ventures were legal for all firms prior to 1976 and enforced by binding contracts, ${ }^{2}$ so oil firms were free to design the collusive agreements optimally. They also did not have to worry about entry. The joint bidding agreements were typically struck shortly before the sale date, which made it difficult for firms who had not invested in seismic surveys to react in time. The gain from reduced competition was also high. The average winning bid in wildcat auctions for the period 1954-79 was 12.8 million dollars (in 1982 dollars). Despite the legality of joint bids, joint bids among the twelve largest bidders, who accounted for $73.8 \%$ of all bids, represented only $18.6 \%$ of total bids submitted by these bidders. Why was the incidence of joint bidding so low?

The low incidence is particularly puzzling since oil and gas leases are common value assets. Buyers are more likely to achieve a consensus on the value of a common

\footnotetext{
${ }^{1}$ See Hendricks, Pinkse and Porter [15] for evidence that supports the claim that oil and gas leases are common value assets.

${ }^{2}$ In late 1975, concerns over bidding collusion caused Congress to pass legislation prohibiting the eight largest private oil firms (Exxon, Gulf, Mobil, Shell, Standard Oil of California, Standard Oil of Indiana, Texaco, and British Petroleum) from bidding jointly on federal leases on the OCS.
} 
value asset. For example, in the case of a pure common value asset, all buyers have the same valuation given the same information. Buyers in common value auctions also need to share their information to determine whether the asset is worth acquiring. By contrast, in private value auctions, each buyer knows whether or not the asset is worth acquiring but, in common value auctions. Information sharing is especially valuable in auctions of risky common value assets like oil and gas leases where the buyers needs to invest after acquiring them. The announced reserve price is relatively small, less than $\$ 100,000$, but the cost of drilling an exploratory well is approximately 1.5 million dollars. The risk of a dry well is high, since only $39 \%$ of the tracts receiving bids in the period 1954-79 were productive (Porter [26]). Thus, the information pooling in oil and gas auctions substantially increases the collusive surplus. Both of these factors suggest that establishing a ring should be easier in auctions of common value assets. Indeed, this is the conventional wisdom. For example, McAfee and McMillan [22] argue that the reason that they focus on the private values case is because the optimal ring mechanism in the pure common value case is simple if members can communicate with each other. Efficiency is attained regardless of which member gets the right to bid in the seller's auction, so an all-inclusive ring can use some exogenous method to pick which of its members should win the right and ask each bidder to report his information. Bidders have no incentive to misrepresent their information, and the winner can determine on the basis of the pooled information whether the asset is worth acquiring.

Our main theoretical finding is that, contrary to conventional wisdom, efficient collusion is always possible in private value environments but not always possible in common value environments. The reason is closely related to the phenomenon known as the "winner's curse". ${ }^{3}$ Fear of the winner's curse causes buyers to bid less aggressively, which leads to inefficient trade. It is possible that no one bids even though at least one of the buyers would be willing to do so if he knew all of the private signals. By contrast, in the ring, there is no winner's curse. Each member knows that, if selected, he will learn the private signals of the other members prior to the acquisition decision and hence will purchase it if and only if his valuation conditional on all of the private signals exceeds investment costs. The efficiency of the ring relative to competitive bidding works to the advantage of buyers with low signals but against a buyer with a high signal. He pays a little less to the seller but a lot more to the other bidders. By contrast, in private value auctions, ownership of the asset is always transferred efficiently whether bidders collude or not. This is because each buyer's willingness to pay depends only upon his own private signal,

\footnotetext{
${ }^{3}$ Bulow and Klemperer [4] document a number of similar counterintuitive results that can arise when bidders bid noncooperatively for common value assets. They show that fear of the winner's curse can cause increases in supply, allocation by rationing and exclusion of potential buyers to increase the prices of common value assets.
} 
and he bids if and only if his valuation conditional on his signal exceeds investments costs.

Our theory predicts that oil firms are unlikely to collude on marginal tracts where priors are pessimistic and competition is low. We test this prediction. One difficulty in testing this prediction is measuring competition. The decision to bid is endogenous, because post-sale drilling costs are non-trivial, and the number of bids submitted is therefore correlated with the inferences firms draw from their signals. We construct a measure of the number of potential bidders for a tract from information on the location of the tracts and which firms bid in the area. A second difficulty is identifying the tracts on which the ring operates. Colluding firms often bid jointly, which is observable since the participants had to identify themselves and their shares in submitting their bid. But solo bidding does not necessarily imply the absence of a ring. In his testimony to the Subcommittee on Monopolies and Commercial Law in February 1976, Darius Gaskins argued that the collusive effects of joint ventures should not be measured solely in terms of tracts receiving joint bids. The negotiations to bid jointly could allow partners to coordinate their solo bids. Indeed, our theoretical results suggest that this could be the case. Equal-sharing may be efficient and incentive compatible in pure common value auctions, but bidders with high signals may be reluctant to join such a ring. Collusive mechanisms with side payments such as the first-price knockout can mitigate (but not entirely solve) this problem. But if the ring uses a mechanism like the knockout auction to coordinate bids, then its presence can be inferred from bidding patterns. We identify rings by their joint bids and propose a test for identifying the set of tracts on which they operate that exploits the locational information. We find no evidence that joint bidding between a pair of firms in one area spills over and affects the likelihood of their bidding against each other in other areas, as Gaskins hypothesized. This suggests that rings typically bid jointly and that solo bids were coordinated only in areas where they bid jointly.

Our main empirical finding is that, based on the incidence of joint bidding, rings rarely operate on tracts where the number of potential bidders is fewer than five. Since the number of potential bidders is highly correlated with the value of the tract, these are tracts where the risk of dry holes is high and information sharing is valuable. This evidence supports the claim that oil and gas leases are common value assets and the prediction that the winner's curse can prevent rings from forming in common value auctions.

As mentioned previously, the theoretical literature on collusion in auctions has focused exclusively on the case of private values with independent signals. Graham and Marshall [12] analyze collusion in second-price sealed bid and English auctions. They show that a second-price knockout auction tournament operated by an outside agent hired by the ring can implement efficient collusion by any subset of ex ante identical bidders. The mechanism satisfies ex ante budget balance but not ex post 
budget balance. Mailath and Zemsky [19] study second-price auctions with heterogenous bidders and establish that efficient collusion by any subset of bidders is possible. McAfee and McMillan [22] study first-price sealed bid auctions and show that, if the ring includes all bidders, then efficient collusion with ex post budget balancing is possible but it requires transfers to be paid from the member with the highest valuation to those with lower valuations. They assume that bidders commit to the ring before they obtain their private information so that the relevant participation constraints are ex ante. Cramton and Palfrey [7] study efficient collusion by an all-inclusive ring in homogenous good industries where firms have private information about costs. They characterize conditions under which it is possible for the lowest cost firm to produce the monopoly output and bribe the other cartel members not to produce, under the threat that defection by any one firm results in either Cournot or Bertrand competition. They also consider the case of common cost uncertainty and show that equal-sharing cartels are unlikely to form when the number of firms is large.

Previous empirical studies of joint bidding in OCS auctions by Mead [23], Erickson and Spann [9], Gaskins and Vann [10], Mead and Sorenson [21], Rockwood [29] and Gilley et al [11] have estimated reduced form models of the determinants of joint bids. These authors typically use the government's estimate of the value of the tract, the winning bid, and/or the number of bids as a measure of ex ante value of the tract. We use our measure of the number of potential bidders as a proxy for ex ante perceptions of value.

The paper is organized as follows. In the next section we describe the way in which the U.S. government auctions its offshore oil and gas leases and how firms form joint ventures. The description motivates our approach of modeling collusion as a problem of mechanism design. The model is presented in Section 3. We focus on a simple comparison: the buyers' expected payoffs if none collude versus their expected payoffs if all collude. In Section 4 we identify conditions under which the first-price knockout auction yields payoffs that satisfy interim participation constraints and characterize the set of all incentive compatible, efficient collusive mechanisms for common value environments with independent signals. In Section 5 we use a parametric example to identify the conditions under which the all-inclusive ring does not satisfy interim participation. Coalitions of subsets of bidders, or partial rings, are discussed briefly in Section 6. In Section 7 we show that the theoretical predictions are consistent with observed bidding patterns in offshore oil and gas auctions. Section 8 provides concluding remarks. 


\section{The Application}

The US government holds the mineral rights to offshore lands more than three miles from the coast, out to the 200 mile limit. Beginning in 1954, the federal government has transferred production rights on its lands to the private sector by a succession of lease sales in which hundreds of leases have been auctioned. A wildcat lease sale is initiated when the Department of Interior (DOI) announces that certain offshore areas are available for exploration, and nominations are invited as to which tracts should be offered for sale. A tract is typically a block of 5,000 or 5,760 acres, or half a block. The number of tracts available in a sale is usually well over one hundred and tracts are often scattered over several different areas. They are sold simultaneously using a first-price, sealed bid auction. The announced reserve price for tracts in our sample is $\$ 15$ per acre. Post-sale drilling costs were approximately one to two million dollars per tract. A participating buyer or consortium of buyers submits a separate bid on each tract that it has an interest in acquiring. A bid is a dollar figure, known as a bonus. At the sale date, DOI opens the envelopes and announces the value of the bids that have been submitted on each tract and the identities of the bidders. The firm or consortium that submits the highest bid on a tract is usually awarded the tract at a price equal to its bid. In practice, the government could and did reject bids above the stated minimum price. The rejection rate was less than $10 \%$ on wildcat tracts and usually occurred on marginal tracts receiving only one bid (Porter [26]).

Prior to the wildcat sale, firms acquire geophysical and geological information about the tracts. They are not permitted to drill exploratory wells. A geophysical company is often hired to "shoot" a seismic survey of a large, roughly 50 block area. The cost of the shoot is approximately $\$ 12$ million and it is usually shared by several oil companies. Alternatively, the geophysical company may finance its own survey, anticipating that it can sell the report to the oil firms at a future date. In either case, the oil companies jointly underwrite the cost of the shoot. After receiving the data from the shoot, each firm identifies key geological features that it believes are evidence of the presence of hydrocarbons. At this point, each firm typically rejects at least half of the tracts in the 50 block area. Since the interpretation of seismic data varies considerably across firms, they frequently select different tracts. Each firm then conducts an in-depth evaluation of the tracts it views as promising to determine whether they are worth bidding for and, if so, how much to bid. In this second stage, the oil firms often purchase more data and shoot "infill" or "cross-diagonal" lines on selected blocks to build a better picture of the substrata. Indeed, the major oil companies often reserve boat time at the time of joint shoot, anticipating their need to do follow up shoots. The cost of the information upgrade on the area is between $\$ 500,000$ to $\$ 1$ million. In addition, the firm must pay for the in-house expertise required to interpret the geophysical data. The rejection rate in the second stage 
is much lower. Each firm typically submits bids on $80 \%$ of the tracts that it has scrutinized more closely.

All firms were allowed to bid jointly prior to 1975 and the joint bidding agreements were enforced by legally binding contracts. Most of the joint bidding agreements are sale-specific, that is, firms who bid jointly in one sale frequently did not do so in other sales. The agreements were typically struck after the firms had invested in the area-wide seismic studies. The procedure is described by Mobil Oil Corporation in its testimony submitted on February 19, 1976 to the House of Representatives, Subcommittee on Monopolies and Commercial Law of the Committee on the Judiciary.

"The bidding groups are formed under a bidding agreement, a formal written document executed by all parties prior to any discussions relating to bonus values. This agreement establishes procedures for arriving at a joint bid and provides for the protection of each individual company in the event agreement cannot be reached. The agreement can either cover the entire sale area or, more commonly, be limited to a specific area of mutual interest (AMI) to the companies involved."

Hendricks and Porter [13] document that equal division is the predominant sharing rule among the major bidders when they submit joint bids, although not when a major (or more than one major) bids with smaller partners. Smaller partners tend to have smaller shares. The agreements did allow firms to adjust their shares on individual tracts, possibly to zero, if they could not agree upon a bid. Mobil describes the joint bidding negotiations as follows:

"Each party suggests the highest amount it is willing to bid. The highest suggested bid becomes the group bid on that particular tract. At this point, companies sometimes drop out of the group if they cannot support the highest suggested bid and no further discussion of bid level on that particular tract is held in the presence on the non-participating parties. Any company that is unwilling to join in the highest suggested bid must drop out. In some instances, a company will take a reduced percentage in the joint bid rather than drop out."4

To avoid strategic drop outs, the agreement typically required each participant to offer their partners equal ownership shares if it wins the tract with a bid that is

\footnotetext{
${ }^{4} \mathrm{~A}$ similar description is given by Andrew Stuart in his article on the Baltimore Canyon sale in the September 11, 1978 issue of Fortune.
} 
not sanctioned by the ring. This provision eliminated the incentive participants may otherwise have had to pretend disinterest in a tract and then outbid the ring. As a result, members either shared in the bids submitted by the ring on tracts within the AMI or they did not bid.

The above description establishes several important facts that are relevant to our model. First, the joint venture agreements are negotiated after the firms have acquired their private information about the tracts. Second, the joint venture agreements cover blocks of tracts, typically 25 to 50 tracts, and not individual tracts. Third, if the firms decide to participate in the joint venture, they know that they are legally committed to jointly evaluate tracts in the AMI and to coordinate their bids according to the mechanism specified in the agreement. And fourth, the allocation decisions are made on a tract-by-tract basis.

\section{The Model}

We model collusion as a problem in mechanism design. Firms can make binding commitments to the ring, and side payments are feasible. The collusive mechanism determines which members get the exclusive right to bid on which tracts, and the transfers among them. We restrict attention to mechanisms that allocate each tract on the basis of the information reported on that tract. The restriction rules out mechanisms that bundle tracts, as well as mechanisms such as the rank-order mechanism studied by Pesendorfer [25] that allocates individual tracts on the basis of information reported on other tracts. The implicit assumption is that buyers have to collude efficiently on each tract in order to collude efficiently on the block of tracts. ${ }^{5}$

The seller sells the representative tract using a first-price sealed bid auction with a pre-announced reserve price. Let $r$ denote the sum of the reserve price and post-sale investment. There are $n$ buyers, labelled $i=1, . ., n$. To qualify as a buyer, a firm has to invest in a survey of the area. The number and identities of the buyers are assumed to be common knowledge. ${ }^{6}$ Thus, investment in the area-wide survey establishes a firm as a serious bidder.

We denote buyer $i$ 's private signal on the representative tract by $S_{i}$. The signals are real-valued and their support normalized to be the unit interval. Let $V$ denote the unknown component that is common to both buyers' valuations.

\footnotetext{
${ }^{5}$ Characterizing efficient collusion in multiple object auctions is a research program unto itself and beyond the scope of this paper. Jackson and Sonnenschein [16] provide an interesting characterization of efficient mechanisms for environments in which number of objects is large.

${ }^{6}$ When firms hire a geophysical survey company to shoot the area, disagreements among them about the design of the shoot sometimes makes it necessary for them to communicate directly with each other. They also frequently reveal themselves as serious bidders when they engage in "infill" surveys.
} 
Assumption 1: $\left(V, S_{1}, . ., S_{n}\right)$ are affiliated and symmetric in $\left(S_{1}, . ., S_{n}\right)$.

Let $F$ denote the cumulative distribution function of $\left(V, S_{1}, . ., S_{n}\right)$ with support $[\underline{v}, \bar{v}] \times$ $[0,1]^{n}$. It is assumed to have a density $f$. Let $F\left(s_{-i} \mid s_{i}\right)$ denote the conditional distribution of $s_{-i}=\left(s_{1}, ., s_{i-1}, s_{i+1}, . ., s_{n}\right)$, the signals of buyer $i$ 's rivals, given $S_{i}=$ $s_{i}$. The value of the tract to buyer $i$ is given by $u\left(V, S_{i}\right)$ where $u$ is non-negative, continuous, and increasing in both arguments. The buyer utilities depend upon the common component in the same manner and each buyer's utility is also allowed to depend upon its own private information. Laffont and Vuong [18] refer to this model as the Affiliated Values (AV) model. It was first introduced by Wilson [30] and is a special case of the general symmetric model of Milgrom and Weber [23]. In the AV model, the signals of the other buyers affect the expected utility of buyer $i$ through their affiliation with $V$ and $S_{i}$, but they do not enter as an argument of the utility function.

The affiliated values model captures most of the special cases that have been considered in the literature. It includes the case of pure common values, in which each buyer's valuation depends only upon the common factor (i.e., $u\left(V, S_{i}\right)=V$ ). It also includes the case of private values, in which a buyer's valuation depends only its own signal (i.e., $\left.u\left(V, S_{i}\right)=S_{i}\right)$. If, in addition, the signals are independently distributed, then the model is called Independent Private Values (IPV); otherwise it is called affiliated private values (APV). Finally, it includes a class of models that have recently received attention, in which the common factor can be expressed as a (deterministic) function of the buyer signals, $V=g\left(S_{i}, S_{-i}\right)$, where $g$ is symmetric, increasing, and continuous. Define $v\left(S_{i}, S_{-i}\right)=u\left(g\left(S_{i}, S_{-i}\right), S_{i}\right)$. Then the restrictions on $u$ and $g$ imply that

$$
s_{i} \geqslant s_{j} \Longrightarrow v\left(s_{i}, s_{j}, s_{-i, j}\right) \geqq v\left(s_{j}, s_{i}, s_{-i, j}\right)
$$

for all $i, j, j \neq i$ and where $s_{-i, j}$ denotes the signals of all buyers other than $i$ and $j$. Each buyer's valuation can be expressed in terms of a common component and a private component. For example, Bulow and Klemperer [4] assume that $V=\sum_{i=1}^{n} S_{i}$ and $v\left(S_{i}, S_{-i}\right)=(1+\alpha) S_{i}+\Sigma_{j \neq i} S_{j}$, where $\alpha>0$. If equality holds for all possible signals, then the model is one of pure common values.

We are primarily interested in comparing the buyers' payoffs in two circumstances: when there is a coalition of all buyers and when individual buyers behave noncooperatively. ${ }^{7}$ If buyers do not collude, they bid individually and competitively on the tracts in the seller's first-price sealed bid auction. The equilibrium payoffs of this auction determines the buyers' participation constraints. If the buyers collude, the ring must decide whether or not to acquire the tract at cost $r$ and how to divide the collusive surplus. A ring mechanism is ex post efficient if (i) the buyer with the

\footnotetext{
${ }^{7}$ One way that this situation can occur is if each buyer has veto power: if any buyer refuses to join the ring, then the ring breaks down.
} 
highest signal is given the exclusive right to purchase the tract and (ii) he does so if and only if the expected value of the tract conditional on the signals of all buyers exceeds $r$. Condition (ii) is the distinguishing feature of common value environments. In private value environments, each buyer knows whether or not he is willing to pay at least $r$ for the asset. In common value environments, buyers need to share their information to determine whether or not their willingness to pay exceeds $r$. The pooling of information is especially valuable if $r$ is large. Note that condition (i) is not necessary in the case of pure common values. If all buyers value the tract equally conditional on the same information, then any allocation satisfying condition (ii) is ex post efficient.

A key issue in specifying the payoffs to bidding competitively (or collusively) is whether buyers infer anything about each other's private information from their participation decision. Cramton and Palfrey [8] refer to the possibility of learning as the leakage problem. ${ }^{8}$ We believe that this problem can be ignored in offshore oil and gas auction because the joint venture decision is taken with respect to a block of tracts and not on individual tracts. If buyer $i$ refuses to join the ring, then the other buyers may infer that buyer $i$ has obtained favorable information about one or more tracts in the area, but they do not know which tracts and, since most are not worth bidding for, the inference is likely to have very little impact on bidding behavior on individual tracts. The situation would be quite different if the decision to collude is taken on a tract by tract basis. In that case, refusal to bid jointly on a tract could cause beliefs about that tract, and therefore bidding behavior, to change. Indeed, we suspect that this is the reason why the geographical unit of the joint venture agreement is not an individual tract but a large block of tracts.

We can now specify the participation constraints. Without loss of generality, we set $n$ equal to two, a restriction that simplifies the notation considerably. Define

$$
w(s, t)=E\left[u\left(V, S_{i}\right) \mid S_{i}=s, S_{j}=t\right]
$$

as buyer $i$ 's expected value of the tract conditional on the event that his signal is equal to $s$ and buyer $j$ 's signal is equal to $t$. We assume that $r$ is less than $w(1,1)$,

\footnotetext{
${ }^{8}$ In an earlier version of this paper, Hendricks and Porter [14] considered an extensive form game in which firms simultaneously voted "yes" or "no" to an equal-sharing joint venture. Firms that voted "yes" formed a ring and firms that voted "no" bid competitively against each other and the ring. More generally, Cramton and Palfrey [8] consider a two-stage game in which firms simultaneously vote for or against a proposed mechanism and have veto power. If the mechanism is unanimously ratified, an all-inclusive ring forms and mechanism is implemented; otherwise the ring does not form and the firms bid competitively against each other. One difficulty with these game forms is the assumption that firms can commit not to renegotiate the outcome of their vote to an alternative mechanism in which all firms gain. For example, if two firms say "no" to an equal-sharing joint venture, each may infer that the other has a high signal and, conditional on this information, be better off colluding.
} 
the highest possible valuation. It will also be convenient to normalize payoffs so that $w(0,0)=0$.

Suppose both buyers use a symmetric bidding strategy $B(s)$ with boundary condition $B(a)=r$ where

$$
a=\inf \left\{s \mid \int_{0}^{s} w(s, t) \frac{f(t \mid s)}{F(s \mid s)} d t \geq r\right\} .
$$

Here $a$ is the cutoff signal below which the buyer does not believe the tract is worth $r$ conditional on winning. It is straightforward to show that equilibrium profits to a buyer in the seller's auction are given by (Milgrom and Weber [23]):

$$
\pi^{N C}(s)=\int_{0}^{s} w(s, t) f(t \mid s) d t-B(s) F(s \mid s)
$$

where

$$
B(s)=r L(a \mid s)+\int_{a}^{s} w(t, t) d L(t \mid s) .
$$

and

$$
L(t \mid s)=\exp \left(-\int_{t}^{s} \frac{f(x \mid x)}{F(x \mid x)} d x\right) .
$$

Note that $\pi^{N C}$ is equal to zero for $s<a$ and increasing for $s>a$.

In our application, firms typically do not form bidding coalitions until after they have acquired their private signals. Thus, the relevant participation constraints are interim: for every possible realization of the signal, a buyer must expect to be at least as well off bidding jointly as he is bidding separately. We shall refer to the first-price sealed bid auction in which buyers bid individually and noncooperatively as the status quo mechanism.

\section{Efficient Collusion}

The standard approach to mechanism design is to exploit the revelation principle and study collusive direct revelation mechanisms. However, as is well known, characterizing the set of incentive compatible collusive mechanisms is quite complicated when signals are affiliated. An alternative approach is to consider a specific indirect mechanism and investigate the conditions under which it generates an ex post efficient allocation that satisfies ex post budget balance and individual rationality. The mechanism that we consider is an augmented form of the first-price knockout auction 
described in McAfee and McMillan [22]. We show that this mechanism always works when the asset is a private value asset, extending the results obtained in the literature. However, when the asset is a common value asset, buyers with high signals may obtain higher payoffs in the status quo mechanism than in the collusive mechanism. We then consider the common value model with independent signals and establish an impossibility result using collusive direct revelation mechanisms. We identify and characterize conditions under which ex post efficiency, budget balance, and individual rationality are not compatible for any indirect mechanism.

\subsection{The First-Price Knockout Auction}

In the knockout auction, each member submits a sealed bid, the member with the highest bid is awarded the exclusive right to acquire the tract at cost $r$ from the seller, and pays his bid to the "losing" buyer. Ties are resolved by randomization. The losing buyer reports his signal to the winning buyer. The winning buyer updates his beliefs about the value of the tract and purchases it from the seller at price $r$ if and only if the expected value of the tract conditional on his signal and the reported signal of the losing buyer exceeds $r$.

In the ring, a bidder learns his rival's signal before he has to decide whether or not to pay $r$ to the seller whereas, in the status quo mechanism, he learns his rival's signal after he pays his bid to the seller, if at all. Let $b$ denote the cutoff signal below which a buyer does not bid in the knockout auction. It is defined as $w(b, b)=r$. The interpretation of $b$ is that it is the lowest signal at which a buyer can win the knockout auction (i.e., $t<b$ ) and be certain that the tract is not worth purchasing conditional on all of the available information. At any higher signal, a buyer is willing to pay a positive amount for the right to purchase the tract at price $r$ since there is some chance that, after winning and learning the other buyer's signal, his valuation exceeds $r$. It follows from Assumption 1 that $b$ is unique.

When valuations are private, the buyer's purchasing decision is contingent only on his own valuation. He bids in either auction if and only if his valuation exceeds $r$, which implies that $a=b$. The difference in the timing of the revelation of a rival's signal does matter when values are affiliated, assuming the reserve price is positive. In that case, applying Assumption 1, we obtain

$$
w(b, b)=r=\int_{0}^{a} w(a, t) \frac{f(t \mid a)}{F(a \mid a)} d t<w(a, a) \Longrightarrow b<a .
$$

Buyers who draw signals between $b$ and $a$ are willing to bid a positive amount in the knockout auction but are not willing to bid in the status quo mechanism. As we shall 
see, the more aggressive bidding by buyers with low signals in the knockout auction can cause buyers with high signals to prefer the status quo mechanism.

Suppose that in the knockout auction both buyers use a symmetric, increasing bid strategy $B^{K}(s)$ with boundary condition $B^{K}(b)=0$. It is straightforward to show that his equilibrium profits are

$$
\pi^{K}(s)=\int_{0}^{s} \max \{w(s, t)-r, 0\} d F(t \mid s)-B^{K}(s) F(s \mid s)+\int_{s}^{1} B^{K}(t) d F(t \mid s)
$$

where

$$
B^{K}(s)=\frac{1}{2} \int_{b}^{s} \max \{w(t, t)-r, 0\} d L^{K}(t \mid s)
$$

and

$$
L^{K}(t \mid s)=\exp \left(-\int_{t}^{s} \frac{2 f(x \mid x)}{F(x \mid x)} d x\right) .
$$

It is easily checked that $B^{K}$ is strictly increasing on the interval $[b, 1]$. For $s<b$, we define $B^{K}(s)=0$. The expected payoff to a ring member is strictly positive and constant for $s$ less than $b$, and strictly increasing in $s$ above $b$.

Since the loser's report does not affect his payment, he has no reason not to tell the truth. In fact, the only circumstance in which he needs to report his signal is when it is less than $b$. Otherwise, the winning buyer can infer his signal from his bid. Symmetry and monotonicity implies that the mechanism selects the buyer with the highest signal provided it exceeds $b$. Ties occur if both buyers submit a bid of zero, but in that case it does not matter who is selected since neither buyer wants to purchase the tract. The selected buyer purchases the tract if and only if $w(s, t)$ exceeds $r$. The transfers among the buyers sum to zero by definition. We have therefore established the following result.

Lemma 1 The first-price knockout auction with information sharing is an ex post efficient mechanism that satisfies ex post budget balance.

It is worth emphasizing the role of symmetry in the above lemma. The first-price knockout selects the buyer with the highest signal, but efficiency requires that the ring select the buyer with the highest valuation conditional on all of the private signals. In symmetric models, these two criteria are equivalent, which explains why information sharing creates no incentive problems.

Do the payoffs of the knockout auction satisfy the interim participation constraints? Bidders with signals below $a$ earn a positive payoff in the knockout auction and zero in the status quo mechanism. Clearly, they are better off in the coalition. In order to compare the payoffs for buyers with signals above $a$, we need the following technical lemma. Subscripts denote partial derivatives. 
Lemma $2 A(s, t) \equiv \frac{f_{2}(t \mid s)}{f(t \mid s)}-\frac{F_{2}(s \mid s)}{F(s \mid s)} \geq 0$ for all $s \leq t$.

Lemma 2 is an implication of affiliation and its proof is relegated to the appendix. Our next lemma compares the slopes of the equilibrium profit functions.

Lemma 3 For any $s>a$.

$$
\begin{aligned}
\frac{d \pi^{K}(s)}{d s}-\frac{d \pi^{N C}(s)}{d s}= & \frac{F_{2}(s \mid s)}{F(s \mid s)}\left[\pi^{K}(s)-\pi^{N C}(s)\right]-\int_{0}^{s} \frac{\partial}{\partial s} \min [r, w(s, t)] f(t \mid s) d t \\
& -\int_{0}^{s} \min [r, w(s, t)] A(s, t) f(t \mid s) d t+\int_{s}^{1} B^{K}(t) A(s, t) f(t \mid s) d t .
\end{aligned}
$$

Lemma 3 generates sufficient conditions under which the payoffs of the knockout auction satisfy the interim participation constraints. It identifies two competing effects on the relative slopes of the equilibrium profit functions: the affiliation of signals effect and the information sharing effect. The affiliation effect favors ring formation. To see why, consider first the benchmark case of independent private values. In a private value environment, the second term in equation (3) is zero since $r=a$. Independence implies $F_{2}(s \mid t)=f_{2}(t \mid s)=0$, which in turn implies that $A(s, t)=0$. As a result, the first, third and fourth terms in equation (3) are also zero in the IPV environment. Since buyers with signals less than $a$ receive a strictly positive payment in the knockout auction and zero in the competitive auction, this result implies that $\pi^{K}(s)$ exceeds $\pi^{N C}(s)$ by a positive constant for all $s>a .^{9}$

Now suppose values are private but signals are (strictly) affiliated. In this case, third term vanishes because

$$
\begin{aligned}
\int_{0}^{s} A(s, t) f(t \mid s) d t & =\int_{0}^{s}\left(\frac{f_{2}(t \mid s)}{f(t \mid s)}-\frac{F_{2}(s \mid s)}{F(s \mid s)}\right) f(t \mid s) d t \\
& =\int_{0}^{s} f_{2}(t \mid s) d t-F_{2}(s \mid s)=0
\end{aligned}
$$

The fourth term is positive by Lemma 2. Since $\pi^{K}(a)$ is greater than $\pi^{N C}(a)$, it then follows from Lemma 3 that $\pi^{K}(s)$ exceeds $\pi^{N C}(s)$ for all $s>a$.

Proposition 4 Suppose values are private. Then the first-price knockout auction is an ex post efficient mechanism that satisfies ex post budget balance and interim participation constraints.

\footnotetext{
${ }^{9}$ Mailath and Zemsky [19] obtain a similar result for second-price auctions.
} 
The key feature of the private value environment is that the buyer's decision to purchase the tract does not depend upon the signal of the other buyer. This situation also arises in an affiliated value environment when the reserve price is zero. It is easily checked that the second and third terms in equation (3) vanish when $r=0$. The difference in slopes between the two profit functions is positive when the profits are equal, as the fourth term is positive and the first is zero in that case. Further, $\pi^{K}(0)$ exceeds $\pi^{N C}(0)$. Hence, the curves do not cross and $\pi^{K}(s)$ exceeds $\pi^{N C}(s)$ for all $s$.

Proposition 5 Suppose the reserve price is not binding. Then the first-price knockout auction with information sharing is an ex post efficient mechanism that satisfies ex post budget balance and interim participation constraints.

McAfee and McMillan [22] show that buyers can collude efficiently and earn higher payoffs when values are private and independently distributed. Proposition 4 extends both of these results to affiliated private values. Proposition 5 extends them to the affiliated value environment with no binding reserve price. The intuition for why affiliation in the absence of information sharing favors the ring is that bidding in the status quo mechanism is relatively more competitive under affiliation.

The information sharing effect works against the formation of an all-inclusive ring. To see this, define $\theta(s)$ as

$$
w(s, \theta(s))=r .
$$

Since $w$ is increasing in both arguments, and $s>a>b$, we have that $\theta(s)<b$. As a result, the second term in equation (3) can be expressed as

$$
\begin{aligned}
\int_{0}^{s} \frac{\partial}{\partial s}\{\min [r, w(s, t)]\} f(t \mid s) d t= & \int_{0}^{\theta(s)} \frac{\partial}{\partial s}\{\min [r, w(s, t)]\} f(t \mid s) d t \\
& +\int_{\theta(s)}^{s} \frac{\partial}{\partial s}\{\min [r, w(s, t)]\} f(t \mid s) d t \\
= & \int_{0}^{\theta(s)} w_{1}(s, t) f(t \mid s) d t \geq 0,
\end{aligned}
$$

where $w_{1}$ is the partial derivative of $w$ with respect to the first argument. The term is a measure of the inefficiency of the competitive auction. When the other buyer's signal lies between 0 and $\theta(s)$, the efficient decision is not to purchase the tract from the seller. This outcome is implemented by the ring but not in the status quo mechanism. As $s$ increases, the effect of the inefficiency decreases since $\theta(s)$ falls. This causes $\pi^{N C}$ to increase more rapidly with $s$ than $\pi^{K}$. Consequently, $\pi^{K}$ can intersect $\pi^{N C}$ at a signal above $a$, violating the participation constraints at higher signals. We provide an example below in which this occurs. Note that the third term 
in equation (3) cannot be signed. It depends on the interaction of the information sharing and affiliation effects.

Why may buyers with high signals prefer to bid competitively for common value tracts? The reason is the winner's curse. Fear of the winner's curse causes buyers to bid cautiously in the status quo mechanism, and buyers with low signals do not participate. The latter leads to inefficient trade, since no one may bid even though at least one of the buyers would be willing to do so if he knew all of the private signals. (The converse is also true - a buyer may purchase the tract in the status quo mechanism when he would not do so if informed of his rival's signal.) By contrast, the ring is efficient. The winning bidder in the knockout auction learns the private signals of the other members, and therefore purchases the tract if and only if his valuation conditional on all of the private signals exceeds investment costs. The efficiency of the ring works to the advantage of buyers with low signals but against a buyer with a high signal. He ends up paying less to the seller but more to the other buyers.

Under the conditions of Propositions 4 and 5, the status quo mechanism is efficient and hence there is no tradeoff between efficient collusion and individual rationality. In common value auctions with a binding reserve price, the status quo mechanism is inefficient and efficient collusion may be incompatible with individual rationality. However, a ring may be able to guarantee its members payoffs that exceed what they can earn in the status quo mechanism if it is willing to sacrifice efficiency.

Proposition 6 The first-price knockout auction without information sharing is a mechanism that satisfies ex post budget balance and interim participation constraints.

The proof of Proposition 6 is given in Appendix A. Note that, as in the case of Propositions 4 and 5, the ring is using a mechanism that implements the same trades as the status quo mechanism. However, it is difficult to imagine oil and gas firms enforcing a joint venture contract that prohibits them from sharing information on individual tracts in the area covered by the agreement when it is ex post optimal for them to do so.

\subsection{Optimal Ring Mechanisms}

The preceding analysis demonstrates that, if information-sharing is important, a buyer with a high signal may prefer the status quo mechanism to an all-inclusive ring which uses a first-price knockout auction to allocate the option to purchase the tract at price $r$. However, this result is not very interesting if there exist other efficient ring mechanisms that do satisfy interim rationality. To study this issue, we exploit the revelation principle and study collusive direct revelation mechanisms. Our main result is that buyers with high signals may prefer the status quo mechanism to any 
efficient ring mechanism, and not just the first-price knockout auction, when signals are independently distributed.

In a collusive direct revelation mechanism, the ring's representative in the seller's auction, and side-payments between the buyers, are determined as functions of the buyers' reported signals. The mechanism is a pair $\{Q, P\}$ where $Q:[0,1]^{2} \rightarrow[0,1]^{2}$ and $P:[0,1]^{2} \rightarrow R^{2}$. Let $x_{i}$ denote the report by buyer $i$. Given reports $\left(x_{1}, x_{2}\right)$, the probability that buyer $i$ obtains the right to bid in the seller's auction is $Q_{i}\left(x_{i}, x_{j}\right)$ and its expected side-payment is $P_{i}\left(x_{i}, x_{j}\right)$. Clearly,

$$
Q_{1}\left(x_{1}, x_{2}\right)+Q_{2}\left(x_{1}, x_{2}\right) \leq 1
$$

for all $\left(x_{1}, x_{2}\right) \in[0,1]^{2}$. We assume that transfers are feasible if they satisfy

$$
P_{1}\left(x_{1}, x_{2}\right)+P_{2}\left(x_{1}, x_{2}\right)=0
$$

for every pair of reported signals $\left(x_{1}, x_{2}\right)$. This requires the ring to balance its budget ex post. A weaker requirement is ex ante budget balance which only requires that transfers between buyers sum to zero on average.

Suppose buyer $j$ reports truthfully. Then the payoff to buyer $i$ with signal $s_{i}$ and report $x_{i}$ is

$$
\pi_{i}\left(s_{i}, x_{i}\right)=E_{s_{j}}\left[Q_{i}\left(x_{i}, s_{j}\right) \max \left\{w\left(s_{i}, s_{j}\right)-r, 0\right\}+P_{i}\left(x_{i}, s_{j}\right)\right] .
$$

Denote $\pi_{i}\left(s_{i}, s_{i}\right)$ by $\pi_{i}\left(s_{i}\right)$. A ring mechanism $\{Q, P\}$ is incentive compatible if for all $s_{i}, x_{i} \in[0,1], i=1,2$,

$$
\pi_{i}\left(s_{i}\right) \geq \pi_{i}\left(s_{i}, x_{i}\right) .
$$

The following standard lemma characterizes the set of incentive compatible mechanisms.

Lemma $7 A$ ring mechanism $\{Q, P\}$ is incentive compatible if and only if for any $s_{i}, x_{i} \in[0,1]$,

$$
\frac{d \pi_{i}\left(s_{i}\right)}{d s_{i}}=E_{s_{j}}\left[Q_{i}\left(s_{i}, s_{j}\right) \frac{\partial}{\partial s_{i}} \max \left\{w\left(s_{i}, s_{j}\right)-r, 0\right\}\right]
$$

and

$$
E_{s_{j}}\left[\left(\partial Q_{i}\left(x_{i}, s_{j}\right) / \partial x_{i}\right) \max \left\{w\left(s_{i}, s_{j}\right)-r, 0\right\}\right] \geq 0 .
$$

Efficiency implies that the buyer with highest valuation is awarded the exclusive right to acquire the tract at price $r$ and does so if and only if the expected value of the tract conditional on $\left(s_{1}, s_{2}\right)$ exceeds $r$. More formally, a direct mechanism is ex post efficient if

$$
Q_{i}\left(s_{i}, s_{j}\right)=\left\{\begin{array}{l}
1 \text { if } s_{i}>s_{j}>\theta\left(s_{i}\right) \\
0 \text { otherwise }
\end{array} .\right.
$$

Combining the incentive compatibility and budget balance with efficiency yields the following characterization. 
Proposition 8 Suppose signals are independently distributed and $w(s, t)>w(t, s)$ for all $s>t$. Then the payoff to buyer $i$ with signal $s$ in any ex post efficient, incentive compatible mechanism that satisfies ex ante budget balance is given by

$$
\pi_{i}^{C}(s)=\pi_{i 0}+\int_{\theta(s)}^{s}[w(s, t)-r] d F(t)-\int_{b}^{s}[w(t, t)-r] d F(t)
$$

for $s>b$ and it is equal to $\pi_{i 0}$ otherwise, where

$$
\pi_{10}+\pi_{20}=2 \int_{b}^{1}[w(t, t)-r][1-F(t)] d F(t) .
$$

Ex post efficiency, incentive compatibility, and ex ante budget balance uniquely determine the payoff of each member of the ring up to a constant. In an anonymous mechanism, the buyers are treated symmetrically, which implies that $\pi_{10}=\pi_{20}$. Any indirect, anonymous ring mechanism that is ex post efficient and satisfies the stronger restriction of ex post budget balance generates identical expected payoffs. It then follows from Lemma 1 that these payoffs can implemented by the first-price knockout auction.

Corollary 9 Suppose signals are independently distributed and $w(s, t)>w(t, s)$ for all $s>t$. Then any efficient, incentive compatible, anonymous ring mechanism can be implemented by a first-price knockout auction with information sharing.

The corollary extends McAfee and McMillan's result for an independent private values model to affiliated value models with independent signals. Of course, the first-price knockout auction is not the only implementable mechanism. A second-price knockout auction also works.

Proposition 10 Suppose signals are independently distributed and $w(s, t)>w(t, s)$ for all $s>t$. Any ex post efficient, incentive compatible, budget balancing ring mechanism satisfies the interim participation constraints if and only if $\pi_{i}^{C}(1)>\pi_{i}^{N C}(1)$ for $i=1,2$.

Proposition 10 establishes a useful necessary and sufficient condition for efficiency, incentive compatibility, and budget balance to conflict with the interim participation constraints. We exploit this condition in the next section to illustrate the conditions under which competitive bidding yields higher profits for high types.

In a pure common value environment with independent signals, efficiency does not require that the buyer with the highest signal win the tract. Ex post efficiency is attained regardless of which buyer wins the tract, as long as the buyers report 
their private signals. In this case, a weak ring, which McAfee and McMillan define as a ring that cannot make transfer payments, can be efficient. The mechanism that awards the right to purchase the tract randomly to one member, and all other members report their private signals, is efficient and incentive compatible. The equal sharing mechanism in which members report their signals, and share costs and revenues equally is another efficient, incentive compatible mechanism. Note, however, that these mechanisms do not generate the same payoffs as the first-price knockout auction. The indeterminacy of the allocation rule implies that efficiency, incentive compatibility, budget balance and anonymity do not uniquely determine the payoffs to ring members.

Proposition 11 Suppose signals are independently distributed, $w(s, t)=w(t, s)$, and

$$
w_{1}(s, t) \frac{F(s)}{f(s)} \geq w_{1}(t, s) \frac{F(t)}{f(t)}
$$

if and only if $s \geq t$. Then any ex post efficient, incentive compatible, budget balancing ring mechanism fails to satisfy the interim participation constraints if $\pi_{i}^{K}(1)<\pi_{i}^{N C}(1)$ for $i=1,2$.

Proposition 11 establishes a useful sufficient condition for checking whether an indirect mechanism such as the equal-sharing mechanism conflicts with interim rationality. If the highest type obtains a higher payoff from bidding competitively than from colluding when the ring uses a first-price knockout auction, then it also prefers the status quo mechanism to a ring that uses the equal-sharing mechanism, or any other efficient, incentive compatible, budget balancing mechanism.

The payoffs are also not uniquely determined in the affiliated values model when signals are affiliated. For instance, the first-price and second-price knockout auctions generate different payoffs. In these cases, the interim participation constraints may be compatible with the above three conditions but the characterization of incentive compatibility is quite complicated. In any case, even if the conditions are compatible, the indirect mechanism that implements those payoffs is not likely to be simple.

Finally, it is worth noting that the analysis of this section also applies to secondprice auctions. It can be shown that the buyer's equilibrium payoffs in the secondprice and first-price auctions are the same when signals are independently distributed.

\section{An Illustrative Example}

When does the equilibrium payoff from competitive bidding exceed the expected payoff to collusion? Is an all-inclusive ring more likely to form in auctions with more buyers? We address these questions using a parametric example. 
Suppose there are three potential buyers and their preferences are given by

$$
u\left(V, S_{i}\right)=V=S_{1}+S_{2}+S_{3} .
$$

For simplicity, we have used equal weights, which makes the model one of pure common values. The signals of the buyer are assumed to be independent random variables with distribution $F(s)=s^{q}$, where $q>0$. The parameter $q$ determines the shape of the distribution. A higher value of $q$ shifts probability mass away from lower signals to higher signals. Higher values of $q$ also means more optimistic priors since

$$
E\left(S_{i}\right)=\frac{q}{1+q} \equiv \mu \text {. }
$$

Note that if $q=1$, signals are uniformly distributed on the unit interval. We use $r$ to parameterize the importance of the information sharing effect.

\subsection{Two Buyers}

We first consider the case in which two of the three potential buyers have searched the area and obtained their signals. To facilitate a comparison with three buyers, we hold the expected value of the tract constant by integrating over $S_{3}$ and replacing its value with $\mu$. If $r>\mu$, the critical cutoff signal for participation in the competitive auction is given by

$$
a_{2}=\frac{1+q}{1+2 q}[r-\mu]
$$

and in the knockout auction, it is given by

$$
b_{2}=\frac{r-\mu}{2} .
$$

Here we subscript the cutoff values by the number of buyers. If $r<\mu$, then $a_{2}=b_{2}=$ 0 , since every type is willing to bid in the seller's auction, and information sharing has no value. Note that the set of types that bid in the knockout but not in the status quo mechanism, $a_{2}-b_{2}$, decreases with $q$ and increases with $r$. Using Proposition 10, we can identify the values of $q$ and $r$ where individual rationality fails to be satisfied by comparing the equilibrium profits of the highest type. The equilibrium payoff to the highest type in the status quo mechanism is

$$
\pi^{N C}(1)=\frac{1-a_{2}^{1+q}}{1+q} .
$$

His payoff in the knockout auction is

$\pi^{K}(1)=\left(\frac{1}{1+2 q}\right)\left[\frac{2 q^{2}+2 q+1}{(1+q)}-\left(\frac{r-\mu}{2}\right)^{1+2 q}\right]-\frac{r-\mu}{2}+\frac{\max \{r-\mu-1,0\}^{1+q}}{1+q}$. 
Details on the derivations of these equations are given in Appendix B.

Figure 1 compares the two payoffs for the highest type in $(r, q)$ space. The solid curve is the locus of points where the highest type's ring profits are equal to his profits in the status quo mechanism. The region below this curve represents the area where highest type earns more from the status quo mechanism than from the ring. For fixed $r$, a higher value of $q$ means that information sharing becomes less valuable, causing the highest buyer to bid relatively more aggressively in the status quo mechanism than the knockout auction. Thus, high values of $q$ favor the ring over the status quo mechanism. For fixed $q$, an increase in $r$ makes information sharing more valuable. This has two effects on the highest type's payoffs. It enhances his strategic advantage in the competitive auction, since the winner's curse is stronger and scares off more types. But it also makes learning the other buyer's signal more valuable. The first effect dominates for low values of $r$ (i.e., $r<1$ ) and the second dominates for high values of $r$ (i.e., $r>1$ ). The trade-off between these two effects accounts for the non-monotonic relationship between $q$ and $r$.

In our application, rings frequently use the equal-sharing mechanism, which is efficient and incentive compatible in our example. Using Proposition 11, we can identify the values of $q$ and $r$ where individual rationality fails for the highest type. The dashed line in Figure 1 corresponds to points where the highest type's profits from the equal-sharing ring are equal to his profits in the status quo mechanism. Clearly, the region where the equal-sharing mechanism is not enforceable is larger than and contains the region where the first-price knockout is not enforceable. Thus, the ring is more likely to form when it allocates the exclusive right to bid in the seller's auction with a first-price knockout auction than when an equal-sharing agreement is employed.

\subsection{Three Buyers}

The critical value for participation in the status quo mechanism is given by

$$
a_{3}=\frac{1+q}{1+3 q} r
$$

and the critical value for participation in the all-inclusive ring is

$$
b_{3}=\frac{r}{3} \text {. }
$$

It is easy to show that the set of types that bid in the knockout but not in the status quo mechanism is larger with three than two buyers (i.e., $a_{3}-b_{3}>a_{2}-b_{2}$ ). The equilibrium payoff to the highest type in the status quo mechanism is

$$
\pi^{N C}(1)=\frac{1}{1+2 q}\left(1-a_{3}^{1+2 q}\right) .
$$


His payoff in the knockout auction does not have a closed form solution and requires numerical integration.

Figure 2 compares the highest type's payoffs in the status quo mechanism and in the first-price knockout ring mechanism. The region below the dashed and solid curves represent the areas where the all-inclusive ring is not enforceable when there are, respectively, two and three buyers. Neither area is a subset of the other, although the area in the three buyer case is smaller. The increase in $n$ has two effects. First, the winner's curse is strengthened, which enhances the high type's strategic advantage in the status quo mechanism but makes information pooling more valuable. When $r$ is low, the strategic advantage is more important and the additional buyer reduces the likelihood that the ring is enforceable. When $r$ is high, information pooling is more important, and the additional buyer makes it more likely for the ring to be enforceable. Second, the level of competition increases. Since the competitive effect is stronger in the status quo mechanism than in the ring mechanism, the area in which the ring is not enforceable is reduced.

We conjecture that the competitive effect dominates as the number of buyers gets large and that, in the limit, the all-inclusive ring satisfies the participation constraints. The problem with studying this issue in the context of a common value model with independent signals is that the value of the tract goes to infinity with the number of signals. The expected value of the tract needs to be held constant as the number of buyers gets large. However, it is not difficult to specify affiliated environments in which even buyers with the highest signal will not want to participate in the status quo mechanism as the number of buyers gets large (i.e., $a_{n}$ converges to 1 ). In these cases, the ring satisfies individual rationality since all buyers make positive profits from collusion. More generally, one wants to show that $\pi^{N C}$ converges to zero faster than $\pi^{K}$, which is likely to be true since aggregate expected profit converges to zero in the status quo mechanism and to a positive constant in the knockout auction.

In summary, the all-inclusive ring is not enforceable when priors are pessimistic (i.e., $q$ is low), acquisition costs are substantial (i.e., $r$ is not too low or too high), and the number of buyers is small.

\section{Partial Rings}

In our application to offshore oil and gas auctions, subsets of buyers can and often do form rings. Before proceeding to the empirical analysis, we briefly discuss the issues involved in studying partial rings.

If there are more than two buyers and no buyer has veto power, then an alternative specification of the participation constraint is the equilibrium payoff to a buyer in a first-price sealed bid auction in which one buyer bids against a ring of size $n-1$. 
The noncolluding bidder gains from the reduction in competition, which makes the all-inclusive ring less stable. For example, McAfee and McMillan study a simple model in which each buyer's private value is an independent Bernoulli random variable. They show that, in equilibrium, the noncolluding bidder is better off than ring members, and that a ring of at least three bidders always forms. Thus, a ring always forms, but the reduced competition effect can explain partial rings. The situation is more complicated when values are affiliated, since the noncolluding bidder is at an informational disadvantage when his rivals form a ring, and this effect could offset the benefit from the reduction in competition. Our focus, however, is on the participation decision of the high signal buyer on marginal tracts when $n$ is small. If the distribution of signals is sufficiently skewed towards low signals, then the buyer with the high signal knows that his rivals are unlikely to bid for the tract, individually or as a ring. In either case, he faces essentially the same tradeoffs, and prefers to bid alone. Furthermore, only one solo bid would typically be observed.

A formal analysis of partial rings in common value environments is well beyond the scope of this paper. When a partial ring of size $n-1$ competes against a noncolluding buyer, the auction is not symmetric: the partial ring observes $n-1$ signals and the noncolluding buyer observes only one signal. It is possible to compute bidding equilibria if the partial ring's information can be summarized by a one-dimensional summary statistic, but the general case of multi-dimensional buyer types has not been solved. The other difficult conceptual issue is that a partial ring has to decide not only whether to bid, but how much to bid, and this decision can affect the incentives of its members to reveal their signals. ${ }^{10}$ In particular, the first-price knockout auction mechanism with information sharing may not have a monotone equilibrium, in which case it is not an ex post efficient mechanism for a partial ring. In fact, this may be the reason why oil and gas firms in our sample typically collude using the equal-sharing mechanism. In a pure common value model, the equal-sharing mechanism may be ex post efficient for any size ring.

\section{Empirical Analysis}

In order to evaluate the predictions of the theoretical model described above, we must confront two measurement issues. First, we require a measure of the level of potential competition on a given tract, and a measure of firms' priors with respect to the likely

\footnotetext{
${ }^{10}$ This problem does not arise when the status quo mechanism is a second-price auction and values are private. The simplifying feature of this auction is that it has a dominant strategy equilibrium in which each buyer bids his valuation. Hence, a noncolluding buyer faces the same high bid whether his rivals form a ring (of any size) or not, assuming the ring selects the member with the highest valuation. Mailath and Zemsky show that, in this case, the all-inclusive ring is in the core.
} 
value of the tract. The decision to bid is endogenous, because post-sale drilling costs are non-trivial, and hence the number of bids submitted will be correlated with the inferences firms draw from their seismic analysis. We therefore construct a measure of the number of potential bidders for a given tract, based on the number of firms active in a neighboring region. This measure of the number of potential bidders is also correlated with firms' prior expectations, because the decision to conduct a detailed seismic analysis depends on those priors. We examine how the propensity to submit joint bids varies with the number of potential bidders, where the latter variable is probably a proxy for both the level of potential competition and for firms' priors.

Second, we require a measure of the incidence of cooperative bidding arrangements. We assume that any such negotiation results in the submission of a joint bid. We first provide some evidence consistent with this assumption. We examine whether there is evidence that bidding negotiations in one area spill over into other areas, in the sense that the participants in the joint bid are less likely to submit competing bids in other regions offered in the same sale. We do not find evidence of these sorts of spillovers. Instead, joint bidding appears to be local to a specific area in a given sale. We therefore examine the joint bidding patterns of the most active bidders to see whether these patterns are consistent with the predictions of our theoretical model.

Our sample consists of the nine sales of wildcat tracts off the coasts of Texas and Louisiana during the period 1954 to 1970 inclusive, in which a total of 1,260 tracts received bids. The information available for each tract receiving at least one bid includes the date of sale; the location; the identity of all bidders and the amounts they bid; the identity of participants in joint bids and their shares in the bid; and whether the government accepted the high bid.

We shall focus on the most active participants in the OCS auctions. Hundreds of firms bid infrequently, and there are many firms that only bid jointly with the major bidders. These latter firms tended to hold smaller shares in the joint bid. Both they and the infrequent bidders were unlikely to be as experienced and informed as the major bidders and were probably not perceived as serious competitors by the major bidders. We focus on the twelve firms and bidding consortia with the highest participation rates in our sample. Table 1 lists these major bidders and their bidding activities. The firms in the Arco bidding consortium pooled their exploration budgets and expertise and bid almost exclusively with each other. We treat this consortium as a single firm. The twelve firms and consortia are designated as large firms, which we call the Big12. All other firms are referred to as fringe firms. For the purposes of this paper, we define a joint bid as one in which two or more large firms participated. All other bids are called solo bids. The first two columns of Table 1 give the number of solo and joint bids of each large firm. ${ }^{11}$ The twelve large firms account for about

\footnotetext{
${ }^{11} \mathrm{~A}$ small number of tracts registered multiple bids by a firm. This problem may in part due to
} 
$75 \%$ of all bids in our sample. ${ }^{12}$

As indicated in Table 1, joint bids account for $18.6 \%$ of the total bids submitted by the Big12. Of the Big12 joint bids, 89.4\% involve pairs of Big12 firms, and the remainder involves triples. (The totals reported for the second and third columns are misleading, since there is some double and triple counting.) There are no joint bids with more than three Big12 participants. It is striking that joint bids are relatively infrequent, despite their legality, and that joint bids usually just involve pairs of large firms.

Note that participation rates in joint bids are not uniform among Big12 firms. Shell rarely participated in joint bids, and Forest never did. Shell had a reputation as being better informed than other major bidders, by virtue of access to "bright spot" seismic technology, and generally having capable seismic geologists. This information superiority may account for their unwillingness to participate in joint bids. In some of the remaining tables, we will restrict attention to what we call the Big10, consisting of the Big12 less Shell and Forest, as this is the set of large firms that bid jointly frequently.

Our measure of $\ell_{t}$, the number of potential bidders on tract $t$, is constructed from information on who bid in the area around this tract, and when. For tracts that were drilled, location is identified by the longitudinal and latitudinal coordinates of the well. Tracts that were not drilled are assigned coordinates by interpolation from nearby tracts that were drilled. ${ }^{13}$ On average a tract covers 0.0463 degrees of longitude and 0.0405 degrees of latitude. A neighborhood for tract $t$ consists of all tracts whose registered locations are within 0.1158 (2.5 times 0.0463$)$ degrees of longitude and 0.1012 (2.5 times 0.0405) degrees of latitude of tract $t$ and that were offered for sale at the same time as or before tract $t$. Ignoring irregular tract sizes and boundary effects, the maximum possible size of a neighborhood is 25 tracts or 125,000 acres.

An obvious approach to defining the number of potential bidders on a tract is simply to count the number of Big12 firms that bid on the tract or in its neighborhood. The rationale is that if a Big12 firm is interested in the area, then it will probably bid on at least one tract. One difficulty with this measure is the treatment of joint bids. Firms that submit solo bids on tract $t$ are counted as potential bidders since they are

classification errors in identifying a firm's subsidiaries and affiliates. We adopted the following rule for these bids. If a subset of the participants in one bid participated in another bid, the latter is dropped. Thus, solo bids of bidders who also submitted joint bids are eliminated. In the other cases, the highest bid is taken and the others dropped.

${ }^{12}$ See Campo, Perrigne, and Vuong [5] for a structural analysis of joint and solo bids within an APV framework.

${ }^{13} \mathrm{~A}$ small number of tracts were sufficiently isolated that it was not possible to interpolate their location from nearby tracts. These tracts were dropped from the sample. 
revealed to be active. For the purposes of this paper, any large firm that participated in a joint bid on tract $t$ is treated as a potential bidder, regardless of how they bid on other tracts in the neighborhood of tract $t$. (In contrast, Hendricks, Pinkse and Porter [15] count all the participants in joint bids as one potential bidder, whether or not they submitted solo bids elsewhere in the neighborhood.) The implicit assumption here is that any participant in a joint bid could have been a solo competitor. We also include firms that did not bid on tract $t$ but submitted solo bids on at least one tract in the neighborhood. Firms that did not bid on tract $t$ and participated in a joint bid on tracts in the neighborhood of tract $t$ are also counted as single competitors.

Our measure of the number of potential bidders on a tract may overstate the true level of competition. For example, all participants in joint bids are treated as potential competitors, as noted above. Also, solo bids are always treated as evidence of competitive behavior. But firms could coordinate bidding strategies by agreeing to bid solo on different sets of tracts rather than bidding jointly. Our measure does not capture this form of collusion. We return to this issue in the next subsection. On the other hand, firms known to be interested in the area but who decided not to bid on any tracts in the neighborhood of tract $t$ are not counted in $\ell_{t}$. We might then underestimate the number of potential bidders.

The final column in Table 1 reports the number of tracts where each large firm is counted as a potential bidder.

\subsection{Evidence of Bid Coordination}

In his Congressional testimony in 1976, Darius Gaskins argued that the collusive effects of joint ventures should not be measured solely in terms of tracts receiving joint bids. The negotiations over which areas to bid jointly could allow partners to learn more about each others' bidding intentions in areas where no joint bids are submitted. In fact, if partners in a joint venture are risk neutral, they could collude by allocating tracts or areas to different partners. For example, the outcome of joint venture agreements could be that firms bid jointly in areas where both firms have searched and each bids solo in areas where it alone has searched. Alternatively, if they use a knockout-style auction on a tract-by-tract basis, then one partner may submit a solo bid and no joint bids may be observed.

In order to assess whether joint bidding negotiations affected competition in areas other than those where joint bids were submitted, we exploit two features of the data. First, if a pair of firms submitted joint bids on some tracts in a given sale, they tended to do so only on a subset of the areas in that sale. Second, these pairs of firms usually submitted joint bids on a subset of the sales.

Our empirical strategy is to examine the bidding behavior of pairs of Big10 firms

when both are potential bidders. We compare their likelihood of submitting bids 
for three sets of tracts. We distinguish between areas where they submitted a joint bid in that sale, areas in sales in which the pair submitted a contemporaneous joint bid in another area, and areas in sales in which no joint bids were submitted by the pair. If joint bidding negotiations affect bidding patterns in other areas being sold contemporaneously, then there will be a difference in bidding patterns between the second and third categories of tracts. That is, one might expect firms that bid jointly in one area to be less likely to compete in other areas offered in the same sale. If so, then it would be a mistake to infer a lack of cooperation from a low incidence of joint bidding.

Tables 2 and 3 look at the propensity for Big10 firms to submit competing solo bids, or to refrain from bidding, for the three sets of tracts described above. Table 2 considers tracts with 2 to 4 potential Big10 bidders, and Table 3 tracts with 5 or more potential Big10 bidders. The unit of observation is, for each tract, all pairs of potential Big10 bidders. Because of this sampling frame, numbers are not directly comparable across rows in Tables 2 and 3, and we instead focus on comparisons across columns. For each pair of potential Big10 bidders on a given tract, the rows report how many times neither bids ("No bid"); only one of the two submits a solo bid, or a joint bid in partnership with another firm (Solo); both submit a solo bid, or a bid in partnership with another firm (Compete); they submit a joint bid with no other large partner (JB2); or they submit a joint bid with another large partner (JB3).

The first column of Table 2 indicates that, for $\ell_{t}$ between 2 and 4 , Big10 firms that bid jointly never submit competing solo bids on other tracts in the neighborhood. They do submit solo bids, but not competing bids on the same tract. This is consistent with our notion that joint bidding negotiations are area-wide, as opposed to tract specific. The corresponding numbers in Table 3 are less striking, but tell a similar story. Competing solo bids are relatively unlikely by firms submitting joint bids in an area, in comparison with areas without joint bidding by that pair.

The second and third columns of Tables 2 and 3 compare bidding propensities in areas with a contemporaneous joint bid by the pair in another area, and areas with no contemporaneous joint bids by the pair. The frequencies reported in the second and third columns of Table 2 are virtually identical. The frequencies in the comparable columns in Table 3 are not identical, but they are similar. In this sense, the data appear to be consistent with the notion that joint bidding negotiations in an area do not differentially affect contemporaneous bidding behavior outside that area. (We should mention a caveat: This conclusion ignores any bias arising from the propensity to be categorized as a potential bidder, by our measure.)

Hendricks and Porter [14] describe an analogous measurement exercise, using a different definition of tracts in a common area, based on clusters of adjacent tracts. (A slightly different sample was used as well, 1954-1975.) For pairs of the seven most frequent bidders, bivariate probit regressions to explain whether either or both of 
the firms bid on individual tracts were estimated for two types of clusters without joint bids by the pair; those in sales with contemporaneous joint bids by the pair, and those in sales without. The bivariate probit regressions included sale specific dummy variables, as well as some tract and cluster specific variables (logarithm of the winning bid, number of other bids submitted, number of tracts in the cluster, etc.). The bivariate probit regressions were calculated separately for each firm pair. The estimated correlation coefficient of the errors did not differ significantly across the two types of clusters, for almost every pair of firms. This is consistent with the evidence presented in Tables 2 and 3. Interestingly, the estimated correlation coefficients was significantly lower for many pairs of firms for the period 1976-1984, following the ban on joint bids among these firms. This pattern is consistent with the firms establishing a pattern of geographic specialization, perhaps as a substitute for joint bidding.

\subsection{Joint Bidding Patterns}

We now examine the incidence of Big12 joint bids, and argue that it is consistent with our theoretical model.

Tables $4 \mathrm{a}$ and $4 \mathrm{~b}$ provide summary statistics on the tracts in our sample. In Table $4 \mathrm{a}$, the tracts are classified by the number of potential Big12 bidders, which ranges from 0 to 12. In Table $4 \mathrm{~b}$, the classification is according to the number of Big10 bidders. Recall that the Big10 consists of the Big12 less Shell and Forest. Recall also that our count of potential bidders includes only Big12 firms, and there is potential competition from fringe firms even when a firm knows it is the only large potential bidder (i.e., $\ell_{t}=1$ ). For each value of $\ell_{t}$, the second column gives the number of tracts, and the third gives the mean high bid. The mean high bid increases from $\$ 434$ thousand on tracts where none of the Big12 firms are potential bidders to $\$ 21.8$ million on tracts where every Big12 firm is a potential bidder. The mean high bid in the sample is $\$ 6.2$ million per tract. (Bids are expressed in 1982 dollars.) Ex ante expectations, as measured by the high bid, are positively correlated with $\ell_{t}$.

The last three columns report the average number of bids per tract, the proportion of those bids submitted by Big12 or Big10 firms, and the proportion of Big12 or Big10 bids that are joint. Big12 firms submit $73.8 \%$ of all bids, and this proportion is roughly constant in $\ell_{t}$. Since the number of bids per tract is increasing in $\ell_{t}$, the average number of bids by fringe firms increases with $\ell_{t}$. On average, there is less than one fringe bid.

The final columns of Tables $4 \mathrm{a}$ and $4 \mathrm{~b}$ reveal that the proportion of Big12 or Big10 bids that are joint is also increasing in $\ell_{t}$, the number of potential large bidders. Since Shell and Forest rarely participate in joint bids, the Big10 numbers are more relevant for this comparison. In particular, the proportion of bids that are joint is increasing 
in $\ell_{t}$ for small numbers of potential large bidders, and roughly constant in $\ell_{t}$ when $\ell_{t}>4$. It is notable that there are few joint bids when $\ell_{t}$ is 2,3 or 4 .

The theory predicts that joint ventures are less likely to form when firms have relatively pessimistic priors. To the extent that $\ell_{t}$ is an indicator of prior expectations, the patterns of joint bidding incidence are consistent with the theoretical prediction. In the instances when there are between two and four potential Big10 bidders, one can also compare Big10 joint bidding incidence according to whether Shell was also a potential bidder. The idea is that firms have more optimistic priors on tracts where Shell is a potential bidder. The Big10 bidders also face more potential competition on these tracts. Of the 361 tracts with 2 to 4 potential Big10 bidders, Shell was also a potential bidder on 148 of them. The Big10 firms submitted 164 bids on this subset, of which $29.5 \%$ were joint. In contrast, in the remaining 213 tracts where Shell was not a potential bidder, only $9.5 \%$ of the Big10 bids submitted were joint. Again, this pattern is consistent with the preceding theoretical model.

Another possible explanation for the pattern is that Big 10 firms who are more likely to bid jointly may have been less likely to bid on low $\ell$ tracts. However, the data did not support this hypothesis.

We have so far ignored the role of the government decision to reject the high bid. It is conceivable that firms do not submit joint bids on tracts with few potential bidders. They may be concerned that their bid will be rejected, if the government reacts to the absence of competition. As Porter [26] notes, high wildcat bids were much more likely to be rejected when there were relatively few bids, and when these bids were low. However, only three high joint bids were rejected in our sample, out of 167 high joint bids, or $1.8 \%$, as opposed to $7.9 \%$ of high solo bids. When one conditions on the level of the high bid, the rejection rule appears to favor joint bids, if anything. (Of course, this does not prove that, had more joint bids been submitted, they would have been accepted with the same frequency.)

\section{Conclusion}

We have shown that the trading inefficiency caused by the "winner's curse" can be an important obstacle to collusion in auctions of common value assets with a binding reserve price or ex post investment. The theory predicts that buyers are unlikely to collude when investment costs are substantial, the number of buyers is small, and priors are relatively pessimistic. These conditions are satisfied in the auctions of federal offshore oil and gas leases on marginal tracts. As our theory predicts, joint bids were less prevalent on these tracts, even though the relative gains from colluding were large, since there was less competition and information sharing was valuable.

An alternative explanation of the patterns in the data was provided in Hendricks 
and Porter [14]. In that paper, our focus was on pre-sale investments necessary for entry as a serious bidder. If rivals cannot observe when these investments are made, free riding is an obstacle to cartel formation. We analyzed a simple environment in which pre-sale investments were zero/one decisions, cartel formation was a veto game in which firms simultaneously announced whether they intended to join (and the cartel formed if and only if all firms said "yes"), and the seller's auction had a binding reserve price with pure common values. In the equilibrium of the three stage game, the incidence of cartel formation is also positively correlated with ex ante perceptions of tract value. The intuition is that firms are willing to participate in a joint bid when they are relatively certain that their rivals are informed, and hence likely to bid in the seller's auction, and this situation is more likely to occur in areas that are perceived to be valuable. We discount this alternative explanation for two reasons. First, as noted in footnote 8, equilibria in which the cartel does not form because both firms announce "no" are not renegotiation-proof. Second, the institutional description in Section 2 suggests that firms do observe whether rivals participate in the first stage group shoot. More generally, they could verify whether a rival had made the requisite investments prior to joint bidding negotiations.

Our results are for legal cartels. However, the analysis may also prove useful for understanding self-enforcing cartels. Athey and Bagwell [1, 2] study optimal collusion in markets where firms receive privately-observed, i.i.d. cost shocks. The firms can communicate with each other to determine who has the lowest cost but they cannot make side-payments to each other. Their modeling approach is to recast the repeated, hidden information game as a static mechanism, similar to that analyzed in the legal cartel literature. They show that, if firms are sufficiently patient, they can use "market share favors" to implement efficient collusion. Our results suggest that it may be more difficult to collude if cost shocks contain a common component. 


\section{References}

[1] Athey, S., K. Bagwell, and C. Sanchirico (2002), "Collusion and Price Rigidity," mimeo.

[2] Athey, S. and K. Bagwell (2001), "Optimal Collusion with Private Information," Rand Journal of Economics, 32(3), 428-465.

[3] Baldwin, L., R. Marshall and J.F. Richard (1997), "Bidder Collusion at Forest Service Timber Sales," Journal of Political Economy, 105, 657-699.

[4] Bulow, J. and P. Klemperer (2002), "Prices and the Winner's Curse," RAND Journal of Economics, 33(1), 1-21.

[5] Campo, I. Perrigne, and Q. Vuong (2001), "Asymmetry in First-Price Auctions with Affiliated Private Values," Journal of Applied Econometrics, forthcoming.

[6] Cramton, P., R. Gibbons, and P. Klemperer (1987), "Dissolving a Partnership Efficiently," Econometrica, 55(3), 615-632.

[7] Cramton, P. and T. Palfrey (1990), "Cartel Enforcement with Uncertainty about Costs," International Economic Review, 31(1), 17-48.

[8] Cramton, P. and T. Palfrey (1995), "Ratifiable Mechanisms: Learning from Disagreement," Games and Economic Behavior, 10(2), 255-283.

[9] Erickson, E.W. and R.M. Spann (1974), "An Analysis of the Competitive Effects of Joint Ventures in the Bidding for Tracts in OCS Offshore Lease Sales," in Market Performance and Competition in the Oil Industry, Hearings Before the Special Subcommittee on Integrated Oil Operations of the Senate Committee on Interior and Insular Affairs, U.S. Government Printing House, Washington, D.C.

[10] Gaskins, D. and B. Vann (1976), "Joint Buying and the Seller's Return: The Case of OCS Lease Sales," in Energy Industry Investigation, Hearings Before the Subcommittee on Monopolies and Commercial Law of the Committee on the Judiciary, House of Representatives, Ninety-Fourth Congress, U.S. Government Printing House, Washington, D.C., 207-235.

[11] Gilley, O.W., G. Karels, and R. Lyon (1985), "Joint Ventures and Offshore Oil Lease Sales," Economic Inquiry, 24, 321-339.

[12] Graham, D. and R. Marshall (1987), "Collusive Bidder Behavior at Single-Object Second-Price and English Auctions," Journal of Political Economy, 95(6), 12171239 . 
[13] Hendricks, K. and R. Porter (1992), "Joint Bidding in the Federal OCS Auctions," American Economic Review, 82, 506-511.

[14] Hendricks, K. and R. Porter (1996), "Joint Bidding and Entry in Federal Offshore Oil and Gas Lease Auctions," mimeo.

[15] Hendricks, K., R. Porter and J. Pinkse (2003), "Empirical Implications of Equilibrium Bidding in First-Price, Symmetric, Common Value Auctions," Review of Economic Studies, 70(1), 33-58.

[16] Jackson, M. O. and H. F. Sonnenschein (2003), "The Linking of Collective Decisions and Efficiency," mimeo.

[17] Klemperer P. (1998), "Auctions with Almost Common Values: The "Wallet Game' and its Applications," European Economic Review, 42, 757-769.

[18] Laffont, J.J. and Q. Vuong (1996), "Structural Analysis of Auction Data," American Economic Review, 86(2), 414-420.

[19] Mailath, G. and P. Zemsky (1991), "Collusion in Second Price Auctions with Heterogeneous Bidders," Games and Economic Behavior, 3(4), 467-503.

[20] Mead, W. J. (1968), "The Competitive Significance of Joint Ventures," Antitrust Bulletin, 12, 819-49.

[21] Mead, W. J. and P.E. Sorensen (1980), "Competition and Performance in OCS Oil and Gas Lease and Lease Development, 1954-1969," Final Report to the U.S. Geological Survey, Reston, Virginia, Contract No. 14-0800001-16552.

[22] McAfee, R.P. and J. McMillan (1992), "Bidding rings," American Economic Review, 82(3), 579-599.

[23] Milgrom, P. and R. Weber (1982), "A Theory of Auctions and Competitive Bidding," Econometrica, 50, 1089-1122.

[24] Myerson, R., (1981), "Optimal Auction Design," Mathematics of Operations Research, 6, 58-73.

[25] Pesendorfer, M. (2000), "A Study of Collusion in First-Price Auctions," Review of Economic Studies, 67, 381-411.

[26] Porter, R. (1995), "The Role of Information in U.S. Offshore Oil and Gas Lease Auctions," Econometrica, 63(1), 1-27. 
[27] Porter, R. and D. Zona (1993), "Detection of Bid Rigging in Procurement Auctions," Journal of Political Economy, 101, 518-538.

[28] Porter, R. and D. Zona (1999), "Ohio School Milk Markets: An Analysis of Bidding," RAND Journal of Economics, 30, 263-88.

[29] Rockwood, A. (1983), "The Impact of Joint Ventures on the Market for OCS Oil and Gas Leases," Journal of Industrial Economics, 31, 453-466.

[30] Wilson, R. (1977), "A Bidding Model of Perfect Competition," Review of Economic Studies, 44, 511-518. 


\section{Appendix A}

\section{Proof of Lemma 2:}

Affiliation implies that $f_{2}(t \mid s) / f(t \mid s)$ is increasing in $t$ and that $f(t \mid s) / F(t \mid s)$ is increasing in $s$. It follows that, for any $s \leq t$,

$$
\frac{f_{2}(t \mid s)}{f(t \mid s)} \geq \frac{f_{2}(s \mid s)}{f(s \mid s)} \geq \frac{F_{2}(s \mid s)}{F(s \mid s)}
$$

where the second inequality follows from

$$
\frac{\partial}{\partial s}\left(\frac{f(t \mid s)}{F(f \mid s)}\right)=\frac{f_{2}(t \mid s)}{F(t \mid s)}-\frac{f(t \mid s) F_{2}(t \mid s)}{F^{2}(t \mid s)} \geq 0 .
$$

Q.E.D.

\section{Proof of Lemma 3:}

In a first-price auction with a reserve price $r$, the equilibrium payoff to a buyer with signal $s>a$ is

$$
\pi^{N C}(s)=\int_{0}^{s} w(s, t) f(t \mid s) d t-B(s) F(s \mid s) .
$$

Differentiating with respect to $s$ and using the envelope theorem, we obtain

$$
\frac{d \pi^{N C}(s)}{d s}=\int_{0}^{s}\left(w_{1}(s, t)+w(s, t) \frac{f_{2}(t \mid s)}{f(t \mid s)}\right) f(t \mid s) d t-B(s) F_{2}(s \mid s) .
$$

where $w_{1}(s, t), F_{2}(x \mid s)$, and $f_{2}(x \mid s)$ represent partial derivatives with respect to $s$. Since

$$
B(s)=\frac{\int_{0}^{s} w(s, t) f(t \mid s) d s}{F(s \mid s)}-\frac{\pi^{N C}(s)}{F(s \mid s)}
$$

it follows that

$$
\frac{d \pi^{N C}(s)}{d s}=\frac{F_{2}(s \mid s)}{F(s \mid s)} \pi^{N C}(s)+\int_{0}^{s}\left[w_{1}(s, t)+w(s, t) A(s, t)\right] f(t \mid s) d t,
$$

where

$$
A(s, t)=\frac{f_{2}(t \mid s)}{f(t \mid s)}-\frac{F_{2}(s \mid s)}{F(s \mid s)}
$$


Equilibrium profits to a buyer with signal $s>b$ in a first-price knockout auction with information pooling is

$$
\pi^{K}(s)=\int_{0}^{s} \max \{w(s, t)-r, 0\} f(t \mid s) d t-B^{K}(s) F(s \mid s)+\int_{s}^{1} B^{K}(t) f(t \mid s) d t .
$$

Differentiation with respect to $s$ and using the envelope theorem, we obtain

$$
\begin{aligned}
\frac{d \pi^{K}(s)}{d s}= & \int_{0}^{s}\left(\frac{\partial}{\partial s}\{\max [w(s, t)-r, 0]\}+\max \{w(s, t)-r, 0\} \frac{f_{2}(t \mid s)}{f(t \mid s)}\right) f(t \mid s) d t \\
& -B^{K}(s) F_{2}(s \mid s)+\int_{s}^{1} B^{K}(t) \frac{f_{2}(t \mid s)}{f(t \mid s)} f(t \mid s) d t .
\end{aligned}
$$

Using the definition of $\pi^{K}(s)$ yields

$$
\begin{aligned}
\frac{d \pi^{K}(s)}{d s}= & \frac{F_{2}(s \mid s)}{F(s \mid s)} \pi^{K}(s)+\int_{0}^{s} \frac{\partial}{\partial s}\{\max [w(s, t)-r, 0]\} f(t \mid s) d t \\
& +\int_{0}^{s} \max \{w(s, t)-r, 0\} A(s, t) f(t \mid s) d t+\int_{s}^{1} B^{K}(t) A(s, t) d F(t \mid s) .
\end{aligned}
$$

The difference in slopes of the two curves at any $s>a$ is

$$
\begin{aligned}
\frac{d \pi^{K}(s)}{d s}-\frac{d \pi^{N C}(s)}{d s}= & \frac{F_{2}(s \mid s)}{F(s \mid s)}\left[\pi^{K}(s)-\pi^{N C}(s)\right]-\int_{0}^{s} \frac{\partial}{\partial s}\{\min [r, w(s, t)]\} f(t \mid s) d t \\
& -\int_{0}^{s} \min [r, w(s, t)] A(s, t) f(t \mid s) d t+\int_{s}^{1} B^{K}(t) A(s, t) f(t \mid s) d t .
\end{aligned}
$$

Q.E.D.

\section{Proof of Proposition 6:}

Equilibrium profits to a buyer with signal $s>a$ in a first-price knockout auction without information pooling is

$$
\pi(s)=(\bar{w}(s)-r-B(s)) F(s \mid s)+\int_{s}^{1} B(t) f(t \mid s) d t,
$$

where

$$
\bar{w}(s)=E[w(s, t) \mid t<s] .
$$


Differentiation with respect to $s$ and using the envelope theorem, we obtain

$$
\frac{d \pi(s)}{d s}=\bar{w}^{\prime}(s) F(s \mid s)+(\bar{w}(s)-r-B(s)) F_{2}(s \mid s)+\int_{s}^{1} B(t) \frac{f_{2}(t \mid s)}{f(t \mid s)} f(t \mid s) d t .
$$

Using the definition of $\pi(s)$ yields

$$
\frac{d \pi(s)}{d s}=\frac{F_{2}(s \mid s)}{F(s \mid s)} \pi(s)+\bar{w}^{\prime}(s) F(s \mid s)+\int_{s}^{1} B(t) A(s, t) f(t \mid s) d t .
$$

Noting that

$$
\bar{w}(s) F(s \mid s)=\int_{0}^{s} w(s, t) f(t \mid s) d t
$$

it follows that

$$
\begin{aligned}
\bar{w}^{\prime}(s) F(s \mid s)= & (w(s, s)-\bar{w}(s)) f(s \mid s) \\
& +\int_{0}^{s} w_{1}(s, t) f(t \mid s) d t+\int_{0}^{s} w(s, t) A(s, t) f(t \mid s) d t .
\end{aligned}
$$

Thus, the difference in slopes of the two curves at any $s>a$ is

$$
\begin{aligned}
\frac{d \pi(s)}{d s}-\frac{d \pi^{N C}(s)}{d s}= & \frac{F_{2}(s \mid s)}{F(s \mid s)}\left[\pi(s)-\pi^{N C}(s)\right] \\
& +(w(s, s)-\bar{w}(s)) f(s \mid s)+\int_{s}^{1} B(t) A(s, t) f(t \mid s) d t,
\end{aligned}
$$

where the second term on the right-hand side is positive since $w(s, t)$ is increasing in $t$ and, due to Lemma 2, the third term is positive. It then follows that

$$
\frac{d \pi(s)}{d s}-\frac{d \pi^{N C}(s)}{d s}>0
$$

whenever $\pi(s)=\pi^{N C}(s)$. Q.E.D.

\section{Proof of Proposition 8:}

Efficiency implies that $Q_{1}\left(s_{1}, s_{2}\right)=1$ if $s_{1}>b$ and $s_{1}>s_{2}>\theta\left(s_{1}\right)$ and equal to 0 otherwise. It then follows from (6) that

$$
\frac{d \pi_{1}(s)}{d s}=\int_{\theta(s)}^{s} w_{1}(s, t) d F(t)
$$

for $s \geq b$ and 0 otherwise. Integrating the above equation yields

$$
\pi_{1}(s)=\pi_{10}+\int_{b}^{s} \int_{\theta(y)}^{y} w_{1}(y, t) d F(t) d y
$$


for $s \geq b$, where $\pi_{10}$ is a constant. Changing integration order in the above expression yields

$$
\pi_{1}(s)=\pi_{10}+K(s)-\int_{b}^{s}[w(t, t)-r] d F(t)
$$

where

$$
K(s)=\int_{\theta(s)}^{s}[w(s, t)-r] d F(t) .
$$

The profit expression for buyer 2 can be derived symmetrically.

From (5),

$$
\pi_{1}(s)=E_{t}\left[Q_{1}(s, t) \max \{w(s, t)-r, 0\}\right]+E_{t} P_{1}(s, t) .
$$

It follows that

$$
E_{t} P_{1}(s, t)=\pi_{1}(s)-K(s)
$$

for $s \geq b$ and is equal to $\pi_{1}(s)$ if $s \leq b$. Thus,

$$
\begin{aligned}
E_{(s, t)} P_{1}(s, t) & =E_{s} \pi_{1}(s)-\int_{b}^{1} K(s) d F(s) \\
& =\pi_{10}-\int_{b}^{1} \int_{b}^{s}[w(t, t)-r] d F(t) d F(s) .
\end{aligned}
$$

Using integration by parts, we obtain

$$
E_{(s, t)} P_{1}(s, t)=\pi_{10}-\int_{b}^{1}[w(t, t)-r][1-F(t)] d F(t) .
$$

Ex ante budget balance implies $E_{(s, t)}\left\{P_{1}(s, t)+P_{2}(t, s)\right\}=0$. It follows that

$$
\pi_{10}+\pi_{20}=2 \int_{b}^{1}[w(t, t)-r][1-F(t)] d F(t) .
$$

\section{Proof of Proposition 10:}

First notice that the profit for a buyer with signal $s$ from the seller's auction, $\pi^{N C}(s)$, is equal to zero for $s \leq a$, and strictly increasing in $s$ for $s \geq a$. Moreover, for $s>a$,

$$
\frac{d \pi^{N C}(s)}{d s}=\int_{0}^{s} w_{1}(s, x) d F(x) .
$$

On the other hand, by Theorem 1, the profit for a bidder with signal $s$ from an efficient, incentive ring mechanism, $\pi^{C}(s)$, is a positive constant when $s \leq b$, and strictly increasing in $s$ for $s \geq b$. Furthermore, for $s>b$,

$$
\frac{d \pi^{C}(s)}{d s}=\int_{\theta(s)}^{s} w_{1}(s, x) d F(x) .
$$


Since $a>b$, it follows that, for any $s>b$,

$$
\frac{d \pi^{N C}(s)}{d s} \geq \frac{d \pi^{C}(s)}{d s}
$$

Therefore, $\pi^{C}(s) \geq \pi^{N C}(s), \forall s \in[0,1]$ if and only if $\pi^{C}(1) \geq \pi^{N C}(1)$. The claim follows. Q.E.D.

\section{Proof of Proposition 11:}

Let

$$
u_{1}(s, \tilde{s})=E_{t}\left[\max [w(s, t)-r, 0] Q_{1}(\tilde{s}, t)-P_{1}(\tilde{s}, t)\right]
$$

and

$$
u_{1}(s)=u_{1}(s, s) .
$$

$u_{2}(t)$ and $u_{2}(t, \tilde{t})$ are similarly defined. An allocation mechanism $\left[Q_{i}, P_{i}\right]$ is incentive compatible if and only if

$$
u_{1}(s, \tilde{s}) \leq u_{1}(s)
$$

and

$$
u_{2}(t, \tilde{t}) \leq u_{2}(t)
$$

for all $s, t, \tilde{s}, \tilde{t} \in[0,1]$. Let $M$ be the set of incentive compatible and ex ante budget balance allocation mechanisms. We first show that if

$$
w_{1}(s, t) \frac{F(s)}{f(s)} \geq w_{1}(t, s) \frac{F(t)}{f(t)}
$$

if and only if $s \geq t$, then $u_{1}(1)+u_{2}(1)$ is maximized in $M$ when

$$
\begin{gathered}
Q_{1}(s, t)=\left\{\begin{array}{l}
1, \text { if } s>t \\
1 / 2, \text { if } s=t \\
0, \text { otherwise }
\end{array}\right. \\
Q_{2}(t, s)=1-Q_{1}(s, t) .
\end{gathered}
$$

Let $\Omega(s)=\{t \mid w(s, t) \geq r\}$ and $\bar{\Omega}=\{(s, t) \mid w(s, t) \geq r\}$. Then necessary and sufficient conditions for IC are

$$
\text { (i) } u_{1}^{\prime}(s)=\int_{\Omega(s)} w_{1}(s, t) Q_{1}(s, t) d F(t)
$$

and

(ii) $\int_{\Omega(s)} w_{1}(s, t) Q_{1}(\tilde{s}, t) d F(t)$ weakly increases with $\tilde{s}$ 
for buyer 1 and similar conditions for buyer 2 .

Since

$$
Q_{1}(s, t)+Q_{2}(t, s)=1,
$$

we let $Q(s, t)=Q_{1}(s, t)$ and $Q_{2}(t, s)=1-Q(s, t)$. Let $u_{1}(0)=u_{01}$. It follows that

$$
\begin{aligned}
E_{s} u_{1}(s) & =\int_{0}^{1} u_{1}(s) d F \\
& =u_{01}+\int_{0}^{1} u_{1}^{\prime}[1-F] d s \\
& =u_{01}+\int_{0}^{1} \int_{\Omega(s)}\left(w_{1}(s, t) \frac{1-F(s)}{f(s)} Q(s, t)\right) d F d F
\end{aligned}
$$

Since, by definition,

$$
u_{1}(s)=E_{t}\left[\max [w(s, t)-r, 0] Q(s, t)-P_{1}(s, t)\right]
$$

it follows that

$$
\begin{aligned}
E_{s, t} P_{1}(s, t) & =E_{s, t}[\max [w(s, t)-r, 0] Q(s, t)]-E_{s} u(s) \\
& =-u_{01}+\int_{0}^{1} \int_{\Omega(s)} I(s, t) Q(s, t) d F d F \\
& =-u_{01}+\int_{\bar{\Omega}} I(s, t) Q(s, t) d F d F,
\end{aligned}
$$

where

$$
I(s, t)=w(s, t)-r-w_{1}(s, t) \frac{1-F(s)}{f(s)} .
$$

Symmetrically, we have

$$
E_{t, s} P_{2}(t, s)=-u_{02}+\int_{\bar{\Omega}} I(t, s)[1-Q(s, t)] d F d F .
$$

Ex ante budget balance requires that

$$
\begin{aligned}
0 & =E_{s, t} P_{1}(s, t)+E_{s, t} P_{1}(s, t) \\
& =-u_{01}-u_{02}+\int_{\bar{\Omega}}(I(t, s)+[I(s, t)-I(t, s)] Q(s, t)) d F d F
\end{aligned}
$$

It follows that

$$
u_{01}+u_{02}=\int_{\bar{\Omega}}(I(t, s)+[I(s, t)-I(t, s)] Q(s, t)) d F d F .
$$


Thus,

$$
\begin{aligned}
u_{1}(1)+u_{2}(1)= & \int_{\bar{\Omega}}(I(t, s)+[I(s, t)-I(t, s)] Q(s, t)) d F d F \\
& +\int_{\bar{\Omega}} \frac{w_{1}(s, t)}{f(s)} Q(s, t) d F d F+\int_{\bar{\Omega}} \frac{w_{1}(t, s)}{f(t)}[1-Q(s, t)] d F d F \\
= & \int_{\bar{\Omega}} I(t, s) d F d F+\int_{\bar{\Omega}}[J(s, t)-J(t, s)] Q(s, t) d F d F
\end{aligned}
$$

where

$$
J(s, t)=w(s, t)-r+w_{1}(s, t) \frac{F(s)}{f(s)} .
$$

Since $w(s, t)-r=w(t, s)-r$, it follows that

$$
J(s, t)-J(t, s)=w_{1}(s, t) \frac{F(s)}{f(s)}-w_{1}(t, s) \frac{F(t)}{f(t)} .
$$

It follows from the assumption that $J(s, t)-J(t, s) \geq 0$ if and only if $s \geq t$. Therefore, $u_{1}(1)+u_{2}(1)$ is maximized in $M$ when the efficient allocation rule is used.

Since the first-price knockout auction implements the efficient allocation rule, to check whether the interim participation constraints are violated it is without loss of generality to compare the payoff from the knockout auction and that from the competitive bidding at the highest signal. The claim follows. Q.E.D. 


\section{Appendix B}

In this appendix, we present the expressions for payoffs and cutoff points used in Section 5 .

\section{B1. Status Quo Mechanism with Two Buyers}

The cutoff point in the status quo mechanism can be calculated as follows: $a_{2}=0$ if $r \leq \mu, a_{2}=1$ if $r \geq(1+3 q) /(1+q)$, and

$$
a_{2}=\frac{1+q}{1+2 q}(r-\mu)
$$

otherwise, where $\mu=q /(1+q)$. Using equation (1), the equilibrium payoff is given by

$$
\pi^{N C}(s)=\frac{1}{1+q}\left(s^{1+q}-a_{2}^{1+q}\right)
$$

for $s \geq a_{2}$ and zero otherwise.

\section{B2. Knockout Auction with Two Buyers}

A first-price knockout auction generates the following profits to a buyer

$$
\pi^{K}(s)=\pi_{0}+\int_{\theta(s)}^{s}(s+x+\mu-r) d x^{q}-\int_{b_{2}}^{s}(2 x+\mu-r) d x^{q}
$$

for $s>b_{2}=\max [0,(r-\mu) / 2]$ and is equal to $\pi_{0}$ otherwise, where

$$
\pi_{0}=\int_{b_{2}}^{1}(2 x+\mu-r)\left(1-x^{q}\right) d x^{q}
$$

and $\theta(s)=\max \{r-\mu-s, 0\}$. Note that

$$
\pi^{K}(1)=\pi_{0}+\int_{\theta(1)}^{1}(1+x+\mu-r) d x^{q}-\int_{b_{2}}^{1}(2 x+\mu-r) d x^{q}
$$

where

$$
\begin{aligned}
\pi_{0} & =\int_{b_{2}}^{1}(2 x+\mu-r)\left(1-x^{q}\right) d x^{q} \\
& =\frac{2 q^{2}}{(1+q)(1+2 q)}-b_{2}+\frac{2}{1+q} b_{2}^{1+q}-\frac{1}{1+2 q} b_{2}^{1+2 q}
\end{aligned}
$$


The second term in the equation for $\pi^{K}(1)$ can be expressed as

$$
\int_{\theta(1)}^{1}(1+x+\mu-r) d x^{q}=2+\mu-r-\frac{1}{1+q}+\frac{1}{1+q} \theta(1)^{1+q}
$$

and the third term can be expressed as

$$
\begin{aligned}
\int_{b_{2}}^{1}(2 x+\mu-r) d x^{q} & =2+\mu-r-2 \int_{b_{2}}^{1} x^{q} d x \\
& =2+\mu-r-\frac{2}{1+q}+\frac{2}{1+q} b_{2}^{1+q} .
\end{aligned}
$$

Putting the terms together yields

$$
\begin{aligned}
\pi^{K}(1)= & \frac{2 q^{2}+2 q+1}{(1+q)(1+2 q)}-\frac{r-\mu}{2}-\frac{1}{1+2 q} b_{2}{ }^{1+2 q} \\
& +\frac{1}{1+q} \theta(1)^{1+q} .
\end{aligned}
$$

\section{B3. Equal Sharing Mechanism with Two Buyers}

The payoff for a buyer with signal $s$ is given by

$$
\pi^{E}(s)=\frac{1}{2} \int_{\theta(s)}^{1}(s+x+\mu-r) d x^{q}
$$

which can be simplified as follows,

$$
\pi^{E}(s)=\frac{q}{1+q}-\frac{r}{2}+\frac{s}{2}+\frac{\theta(s)^{1+q}}{2(1+q)}
$$

for all $s \in[\theta(1), 1]$ and 0 otherwise.

\section{B4. Status Quo Mechanism with Three Buyers}

Define

$$
w(s, t)=E\left[s_{1}+s_{2}+s_{3} \mid s_{1}=s, \max \left\{s_{2}, s_{3}\right\}=t\right] .
$$

In the status quo mechanism, it can be verified that there is a symmetric equilibrium bidding strategy $B(s)+r$, where

$$
B(s)=\frac{\int_{a_{3}}^{s}[w(x, x)-r] d F^{2}}{F(s)^{2}}
$$


and

$$
\int_{0}^{a_{3}}\left[w\left(a_{3}, x\right)-r\right] d F^{2}=0
$$

The payoff is

$$
\pi^{N C}(s)=\int_{0}^{s}[w(s, x)-r] d F^{2}-\int_{a_{3}}^{s}[w(x, x)-r] d F^{2} .
$$

Since in the example

$$
w(s, t)=s+\frac{1+2 q}{1+q} t
$$

it can be computed that

$$
a_{3}=\frac{1+q}{1+3 q} r
$$

and

$$
\pi^{N C}(s)=\frac{1}{1+2 q}\left(s^{1+2 q}-a_{3}^{1+2 q}\right) .
$$

Note that $a_{3}>a_{2}$ if and only if $r<(1+3 q) /(1+q)$. If $r \geq(1+3 q) /(1+q)$ then $a_{2}=a_{3}=1$.

\section{B5. Knockout Auction with Three Buyers}

To determine the cartel payoffs, define

$$
\bar{w}(s, t)=E\left[\max \left[0, s_{1}+s_{2}+s_{3}-r\right] \mid s_{1}=s, \max \left\{s_{2}, s_{3}\right\}=t\right] .
$$

It can be shown that the interim payoff for a cartel member with signal $s$ is given by

$$
\begin{aligned}
\pi^{K}(s)= & \int_{0}^{1} \int_{0}^{s}\left(\bar{w}(s, t)-\frac{1-F(s)}{f(s)} \bar{w}_{1}(s, t)\right) d F(s) d F^{2}(t) \\
& +\int_{0}^{s} \int_{0}^{x} \bar{w}_{1}(x, t) d F^{2} d x .
\end{aligned}
$$

It follows that

$$
\pi^{K}(1)=\int_{0}^{1} \int_{0}^{s} J(s, t) d F^{2}(t) d F(s)
$$

where

$$
J(s, t)=\bar{w}(s, t)+\frac{F(s)}{f(s)} \bar{w}_{1}(s, t) .
$$

In the example,

$$
\bar{w}(s, t)=\int_{0}^{t} \max \{s+t+x-r, 0\} d x^{q} / t^{q} .
$$


If $s+t>r$, then

$$
\bar{w}(s, t)=s+\frac{1+2 q}{1+q} t-r .
$$

If $s+t \leq r$ and $s+2 t \geq r$, then

$$
\bar{w}(s, t)=s+\frac{1+2 q}{1+q} t-r+\frac{(r-s-t)^{1+q}}{(1+q) t^{q}} .
$$

If $s+2 t<r$, then $\bar{w}(s, t)=0$.

Since the slope of the cartel payoff is zero when $\bar{w}(s, t)=0$ for all $t \leq s$, it follows that $b_{3}=r / 3$. Note that $b_{3}<b_{2}$ if and only if $r>3 \mu$. Moreover, since

$$
\begin{aligned}
& a_{3}-b_{3}=\frac{2 r}{3(1+3 q)}, \\
& a_{2}-b_{2}=\frac{r-\mu}{2(1+2 q)},
\end{aligned}
$$

it can be verified that $a_{3}-b_{3}>a_{2}-b_{2}$ since $r \leq 3 . \pi^{K}(1)$ can be computed numerically. 


\section{$\underline{\text { Table } 1}$}

\section{Wildcat Bidding by the Twelve Most Active Firms and Consortia, 1954-1970}

Firms and Consortia

Number of Joint Joint Bids Total Solo Bids Bids in Pairs Bids

Arco/Getty/Cities/Cont.

Standard Oil of California

Standard Oil of Indiana

Shell Oil

Gulf Oil

Exxon

Texaco

Mobil

Union Oil of California

Phillips

Sun Oil

Forest

Total

$\begin{array}{rrrr}437 & 114 & 105 & 551 \\ 408 & 76 & 76 & 484 \\ 132 & 276 & 257 & 408 \\ 444 & 3 & 3 & 447 \\ 201 & 81 & 48 & 282 \\ 325 & 42 & 35 & 367 \\ 114 & 178 & 148 & 292 \\ 48 & 163 & 134 & 211 \\ 95 & 201 & 157 & 296 \\ 98 & 65 & 62 & 163 \\ 241 & 93 & 69 & 334 \\ 195 & 0 & 0 & 195 \\ & & & \\ 2738 & 625 & 559 & 3363\end{array}$




\section{$\underline{\text { Table } 2}$}

Big10 Pair Bidding with 2-4 Potential Big10 Bidders

\begin{tabular}{|l|l|l|l|}
\hline & $\begin{array}{l}\text { Joint Bid in } \\
\text { Area }\end{array}$ & $\begin{array}{l}\text { Joint Bid in } \\
\text { Sale }\end{array}$ & $\begin{array}{l}\text { Sales with } \\
\text { No Joint Bids }\end{array}$ \\
\hline \# of Tracts & 198 & 2,146 & 13,901 \\
\hline No Bid & 96 & 1,545 & 10,003 \\
\hline & $48.5 \%$ & $72.0 \%$ & $72.0 \%$ \\
\hline Solo & 12 & 569 & 3,662 \\
\hline & $6.1 \%$ & $26.5 \%$ & $26.3 \%$ \\
\hline Compete & 0 & 32 & 236 \\
\hline & & $1.5 \%$ & $1.7 \%$ \\
\hline JB2 & 63 & 0 & 0 \\
\hline & $31.8 \%$ & & \\
\hline JB3 & 27 & 0 & 0 \\
\hline & $13.6 \%$ & & \\
\hline
\end{tabular}




\section{$\underline{\text { Table } 3}$}

Big10 Pair Bidding with 5-10 Potential Big10 Bidders

\begin{tabular}{|l|l|l|l|}
\hline & $\begin{array}{l}\text { Joint Bid in } \\
\text { Area }\end{array}$ & $\begin{array}{l}\text { Joint Bid in } \\
\text { Sale }\end{array}$ & $\begin{array}{l}\text { Sales with } \\
\text { No Joint Bids }\end{array}$ \\
\hline \# of Tracts & 1,780 & 2,777 & 28,383 \\
\hline No Bid & 727 & 1,281 & 12,401 \\
\hline & $40.8 \%$ & $46.1 \%$ & $43.7 \%$ \\
\hline Solo & 322 & 1,071 & 10,991 \\
\hline & $18.1 \%$ & $38.6 \%$ & $38.7 \%$ \\
\hline Compete & 67 & 425 & 4,991 \\
\hline & $3.8 \%$ & $15.3 \%$ & $17.6 \%$ \\
\hline JB2 & 493 & 0 & 0 \\
\hline & $27.7 \%$ & & \\
\hline JB3 & 171 & 0 & 0 \\
\hline & $9.6 \%$ & & \\
\hline
\end{tabular}




\section{Table 4a}

Bidding Behavior Conditional on Level of Big 12 Competition

\begin{tabular}{rrrrrrr} 
& & & & & & \\
Nids per & Big 12 Bids & Joint Big12 \\
\cline { 5 - 7 } NPot12 & Tracts & Mean High Bid & Tract & All Bids & All Big 12 \\
0 & 14 & $\$$ & 434,425 & 1.21 & $0.0 \%$ & NA \\
1 & 110 & $\$$ & $1,480,887$ & 1.23 & $74.8 \%$ & $0.0 \%$ \\
2 & 74 & $\$$ & $2,315,983$ & 1.69 & $69.6 \%$ & $3.4 \%$ \\
3 & 130 & $\$$ & $2,360,185$ & 1.92 & $80.3 \%$ & $8.0 \%$ \\
4 & 136 & $\$$ & $2,936,417$ & 2.32 & $70.3 \%$ & $14.0 \%$ \\
5 & 70 & $\$$ & $4,011,824$ & 2.47 & $76.9 \%$ & $16.5 \%$ \\
6 & 52 & $\$$ & $4,502,450$ & 3.42 & $82.6 \%$ & $19.7 \%$ \\
7 & 77 & $\$$ & $5,451,971$ & 4.03 & $71.6 \%$ & $18.0 \%$ \\
8 & 159 & $\$$ & $5,936,896$ & 3.49 & $78.9 \%$ & $19.4 \%$ \\
9 & 132 & $\$$ & $8,007,384$ & 4.42 & $73.8 \%$ & $20.5 \%$ \\
10 & 128 & $\$$ & $9,136,267$ & 5.75 & $75.3 \%$ & $20.6 \%$ \\
11 & 113 & $\$$ & $10,487,946$ & 5.68 & $73.5 \%$ & $23.5 \%$ \\
12 & 65 & $\$$ & $21,815,490$ & 8.32 & $66.0 \%$ & $24.1 \%$ \\
6.47 & 1260 & $\$$ & $6,154,622$ & 3.62 & $73.8 \%$ & $18.6 \%$
\end{tabular}




\section{Table $4 \mathrm{~b}$}

Bidding Behavior Conditional on Level of Big 10 Competition

\begin{tabular}{rrrrrrr} 
& & & & Bids & Big 10 Bids & Joint Big 10 \\
\cline { 5 - 7 } NPot10 & Tracts & Mean High Bid & Tract & All Bids & All Big 10 \\
0 & 45 & $\$$ & 877,014 & 1.27 & $0.0 \%$ & NA \\
1 & 122 & $\$$ & $1,847,792$ & 1.42 & $54.9 \%$ & $0.0 \%$ \\
2 & 85 & $\$$ & $2,479,667$ & 1.84 & $60.3 \%$ & $7.4 \%$ \\
3 & 180 & $\$$ & $2,552,783$ & 2.02 & $59.8 \%$ & $16.6 \%$ \\
4 & 96 & $\$$ & $3,852,841$ & 2.77 & $59.8 \%$ & $18.2 \%$ \\
5 & 73 & $\$$ & $5,374,535$ & 3.70 & $58.1 \%$ & $23.6 \%$ \\
6 & 101 & $\$$ & $4,783,250$ & 3.52 & $56.2 \%$ & $24.0 \%$ \\
7 & 144 & $\$$ & $6,642,102$ & 3.95 & $61.9 \%$ & $22.4 \%$ \\
8 & 139 & $\$$ & $8,483,068$ & 5.11 & $60.8 \%$ & $27.1 \%$ \\
9 & 165 & $\$$ & $9,254,145$ & 5.08 & $62.9 \%$ & $25.8 \%$ \\
10 & 110 & $\$$ & $17,379,913$ & 7.28 & $61.2 \%$ & $27.1 \%$ \\
5.47 & 1260 & $\$$ & $6,154,622$ & 3.62 & $59.7 \%$ & $22.8 \%$
\end{tabular}


Figure 1

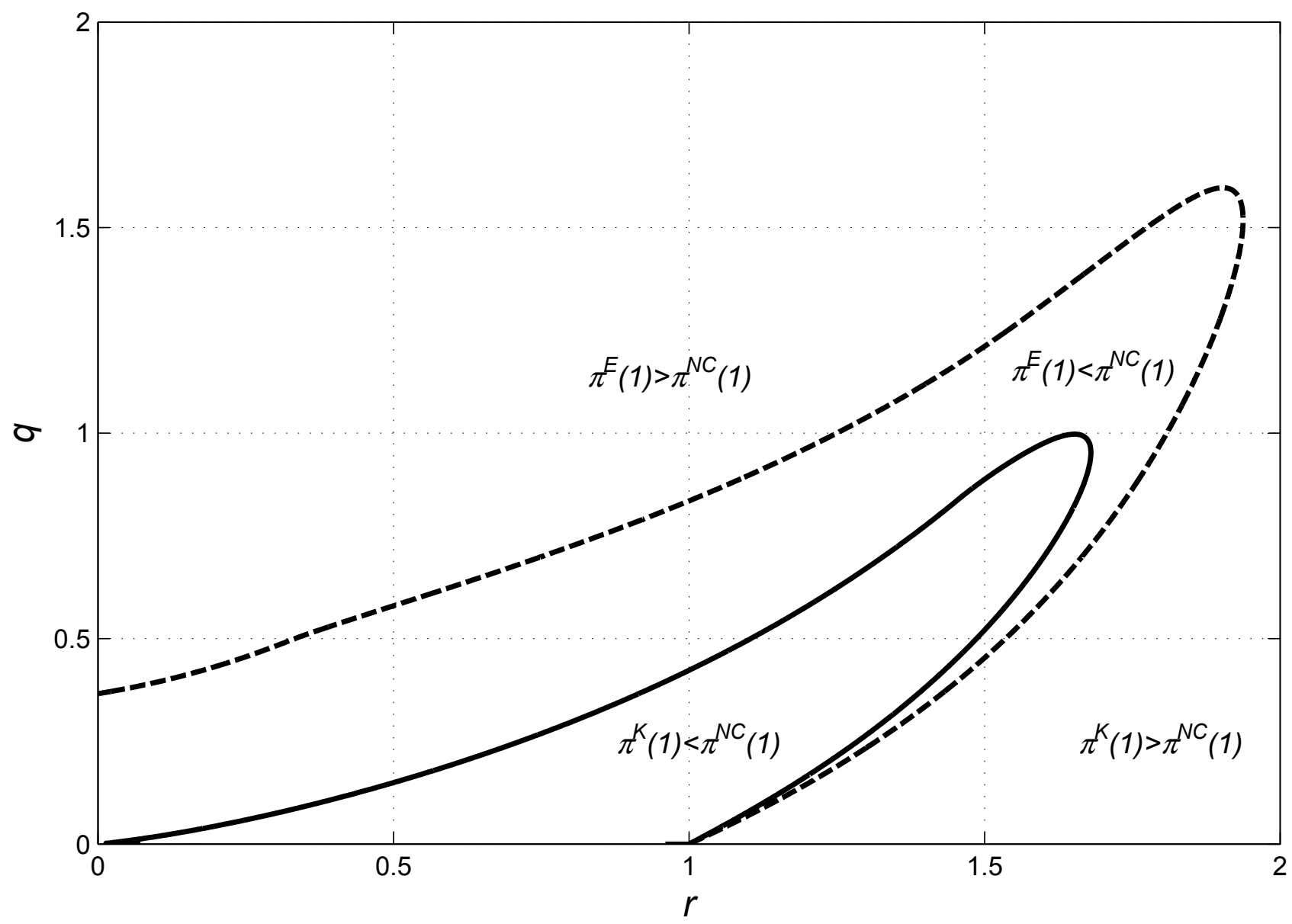


Figure 2

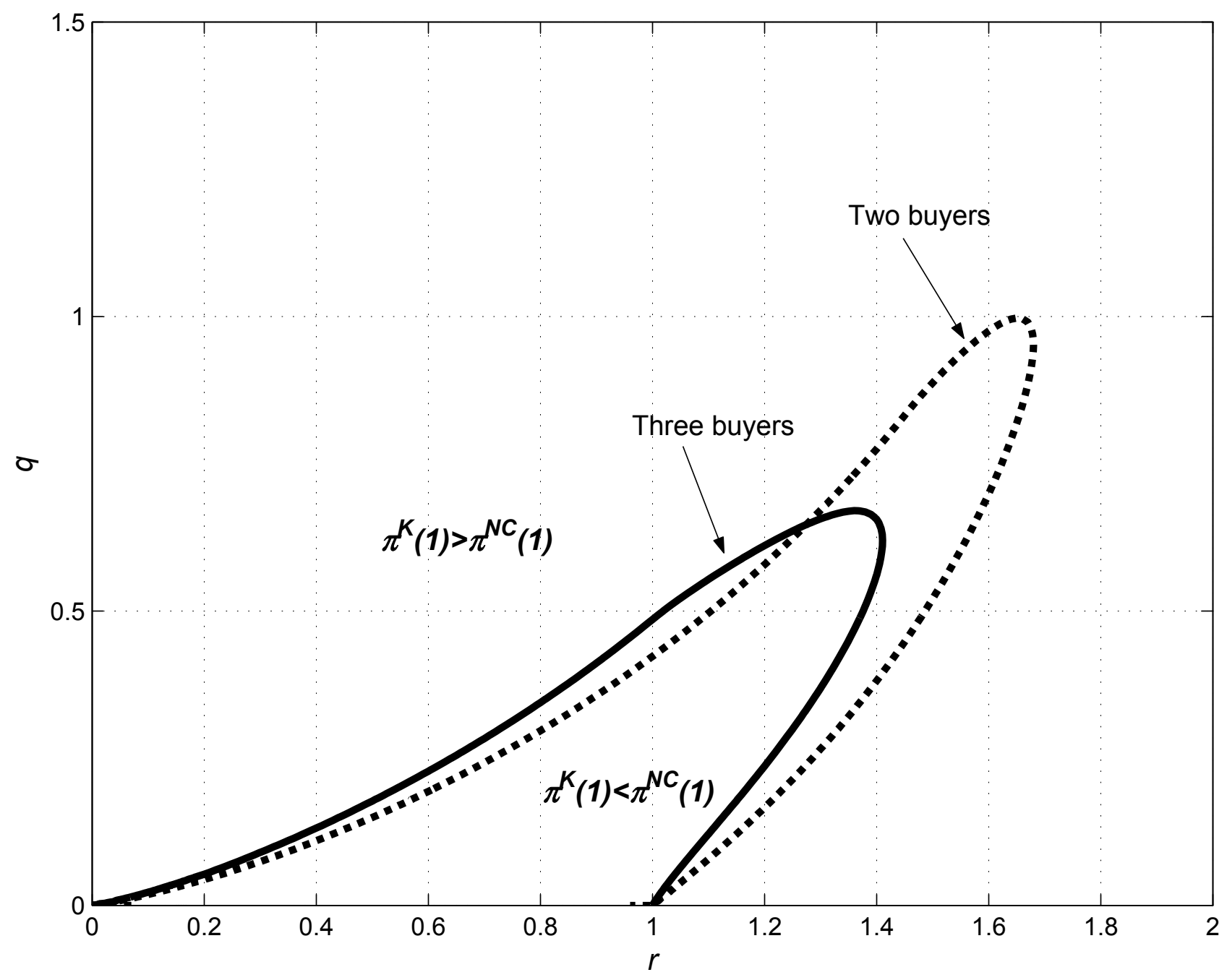

